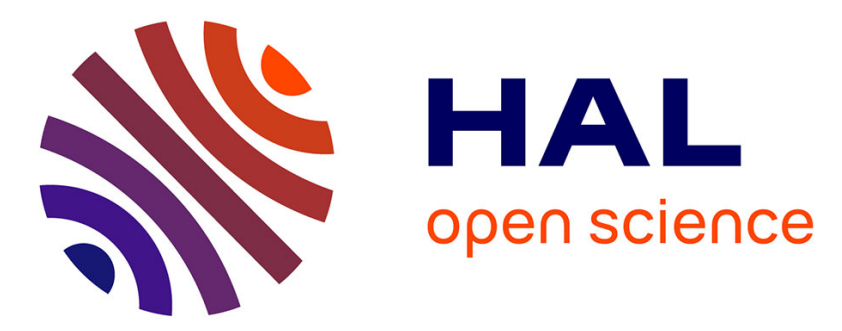

\title{
Optimisation of the aggregation and execution rates for intersecting operation sets: an example of machining process design
}

\author{
Alexandre Dolgui, Genrikh Levin, Boris Rozin
}

\section{To cite this version:}

Alexandre Dolgui, Genrikh Levin, Boris Rozin. Optimisation of the aggregation and execution rates for intersecting operation sets: an example of machining process design. International Journal of Production Research, 2020, 58 (9), pp.2658-2676. 10.1080/00207543.2019.1629668 • hal-02556267

\section{HAL Id: hal-02556267 https://hal.science/hal-02556267}

Submitted on 27 Apr 2020

HAL is a multi-disciplinary open access archive for the deposit and dissemination of scientific research documents, whether they are published or not. The documents may come from teaching and research institutions in France or abroad, or from public or private research centers.
L'archive ouverte pluridisciplinaire HAL, est destinée au dépôt et à la diffusion de documents scientifiques de niveau recherche, publiés ou non, émanant des établissements d'enseignement et de recherche français ou étrangers, des laboratoires publics ou privés. 


\section{Preprint}

[article published in International Journal of Production Research]

Alexandre Dolgui, Genrikh Levin \& Boris Rozin (2020) Optimisation of the aggregation and execution rates for intersecting operation sets: an example of machining process design, International Journal of Production Research, 58:9, 2658-2676,

DOI:10.1080/00207543.2019.1629668

https://www.tandfonline.com/doi/full/10.1080/00207543.2019.1629668 


\title{
OPTIMIZATION OF THE AGGREGATION AND EXECUTION RATES FOR INTERSECTING OPERATION SETS: AN EXEMPLE OF MACHINING PROCESS DESIGN
}

\author{
Alexandre Dolgui ${ }^{*}$ Genrikh Levin ${ }^{* *}$ and Boris Rozin ${ }^{* *}$ \\ *IMT Atlantique, CNRS-LS2N, B.P. 20722 F-44307 NANTES Cedex 3, France \\ (e-mail: alexandre.dolgui@imt-atlantique.fr) \\ ** United Institute of Informatics Problems, National Academy of Sciences of Belarus \\ Surganov Str, 6, 220012, Minsk, Belarus \\ (e-mail: \{levin,rozin\}@newman.bas-net.by)
}

\begin{abstract}
A sequence of multiple parts is processed on a multi-position transfer line of conveyor type. This sequence consists of identical subsequences (batches). The sets of operations executed for each part at each position are given and these sets for different parts can intersect. Some operations executed at one position can be aggregated into blocks of operations. Each block is executed at a uniform rate (in particular, feed per minute) by a common drive unit. The set of potentially feasible blocks is specified. We consider the situation when the sets of operations for different blocks do not intersect and each potential block can be executed either completely aggregated (i.e. as one block) or completely disaggregated (individually). Aggregation reduces the investment costs, but can increase the consumption of tools due to excluding the individual selection of rates for aggregated operations. The accepted option of the aggregation and the rates of operations remain invariable during the line functioning. The problem is to select the optimal option of aggregation and rates of all operations that minimize the total batch processing cost while ensuring the required line productivity. A mathematical model of the problem and a two-level decomposition method for its solution are proposed. The statement of the problem and the results of its solution are illustrated on a real industrial example. The developed model and method can be applied to solve similar problems arising in other domains.
\end{abstract}

Keywords: Transfer lines, Batch processing, Aggregation of operations, Operation rate, Operation costs and times, Optimization.

\section{Introduction}

In last decades, significant attention was paid to the process planning for complexes of interrelated operations in various engineering, organizational and production systems (see, for example, Szadkowski 1971; Alting and Zhang 1989; Boysen, Fliedner and Scholl 2007; Bukchin and Rubinovitz 2003; Halevi 2003; Battaïa and Dolgui 2013). The development of models and methods for joint optimization of the structure of these complexes and execution rates of their operations is of considerable scientific and practical interest. 
In this paper, one of the possible approaches to solve such problems is developed. It is illustrated with an example of optimization of transfer line structure and parameters for multi-product batch machining. A multi-position single-flow transfer line of conveyor type is considered (see, in particular, Dolgui et al. 2016, Battaïa et al. 2017).

It is assumed that input sequence of parts is composed of identical sub-sequences of parts (batches). A set of all operations which must be executed at the line for each part as well as an assignment of the operations to the line positions (stations) are given. The term "operation" refers to a set of interrelated machining steps (e.g., milling, drilling, reaming etc.) that is considered as an indivisible action executed at one position (station) by a common drive unit.

The working stroke and range of possible values of the feed per minute used to process a specific part by a drive unit dealing with an operation are given for all parts and operations.

For the sake of terminological generality with other possible application areas, the working stroke will be considered as the volume of operation and will be given for each pair "operation-part". Similarly, the feed per minute employed for an operation will be considered as the operation rate and also defined for each pair "operation-part". It is assumed that, with a sufficient accuracy for the considered stage of the manufacturing process design, selected operation rates determine all other machining conditions of operations (cutting speeds, feeds per revolution, etc. for all their machining steps) taking into account the corresponding machining technologies (see, for example, Levin and Rozin 2009).

Parts are machined successively one by one at each working position in the order of their arrival and in the order of location of the positions in the transfer line. At each time point only one part is disposed at each position. Sets of operations executed at a position for different parts can intersect.

At the stage of the machining process planning some operations can be aggregated into blocks. All operations of the same block are executed simultaneously by using the same drive unit with a common operation rate (for example, by using a common multi-spindle head). The volume of each block of operations is the maximum of volumes of its operations.

The aggregation of operations into blocks reduces investment and maintenance costs but excludes the possibility of individual selection and optimization of operation rates for aggregated operations. The latter can lead, in particular, to an increase of operation durations, operating costs, the cost and time related to the consumption of tools and their replacement. Feasibility of an aggregation depends on both the mutual disposal of the machined features of the parts and the capabilities of the available equipment.

The set of potentially feasible blocks is assumed to be specified. 
The paper deals with the case when all operations of the same potential block can be performed either completely aggregated (in the block) or completely disaggregated (individually). It is impossible to execute a part of block in the aggregated manner and the rest individually, otherwise the corresponding part of block is considered as a block.

The selected option of aggregation of operations and their rates largely determine the structure and parameters of the machining process, the layout of the line as well as the characteristics of the line equipment. Therefore, this decision significantly affects the output of the line, the line investment cost, operational cost, tool consumption and, consequently, the total cost of batch machining.

The objective is to select aggregation options and rates for all operations minimizing the total cost of batch machining while providing a required output of the line.

The rest of the paper is organized as follows. A brief review of literature related to the considered problem is reported in Section 2. The problem statement and its mathematical model are presented in Section 3. The solution techniques based on two-level decomposition scheme are described in Section 4. Section 5 is devoted to industrial example illustrating the proposed approach. Finally, Section 6 includes conclusion remarks. The appendix contains a table of notations used in the paper.

\section{Breaf review of literature}

One of the first papers on optimization of execution of operation sets in machining systems with a graph approach was published by Szadkowski (1971). Several aspects of the structural and parametric optimization of machining processes in a transfer line of conveyor-type composed of aggregate machines were studied by Levin and Tanaev (1978). Comprehensive surveys of machining process planning articles are presented by Alting and Zhang (1989), and Halevi (2003). A number of articles, e.g. (Bennett and Yano 2004), (Singh and Jebaraj 2005), and (Gupta et al. 2011), were devoted to problems of complex process planning including equipment selection. Singh and Jebaraj (2005) used feature-based environment and operation-based feature mapping to design the set of operations for machining a given part. Then they applied genetic algorithm to find an optimal (for the selected objective function) sequence of operations, machines and cutting tools with respect to a given factory environment. Gupta et al. (2011) developed an integrated model to find an optimal sequence of operations for a given set of machines, tools and machining conditions minimizing the cost of machining cylindrical parts. Bennett and Yano (2004) developed models for selection of equipment in multi-product production systems taking into account capacity consumption, product routing, and impact on the environment. 
Joint problems of process planning and scheduling were considered by Mohapatra, Benyoucef and Tiwari (2013). In (Koren, Gu and Guo 2018) the impact of configuration of production system for high-volume manufacturing on the enterprise long-term profitability considering investment cost, throughput, responsiveness to market changes and product quality, was analyzed.

A number of process planning studies have been devoted to the problems of machining conditions optimization, e.g. Arezoo, Ridgway and Al-Ahmari (2000), Cakir and Gurarda (2000). Arezoo, Ridgway and Al-Ahmari (2000) addressed the problems of selection of cutting tools and conditions of machining operations using an expert system. Cakir and Gurarda (2000) suggested a procedure to calculate machining conditions of multi-tool multi-pass milling operations to minimize the production cost.

Among other related problems studied in the literature should be mentioned machining and assembly line balancing problems, that consider allocation of operations to working stations, e.g. Boysen, Fliedner and Scholl (2007), Bukchin and Tzur (2000), Bukchin and Rubinovitz (2003), Dolgui, Guschinsky and Levin (2009), Kara et al. (2011), Battaïa and Dolgui (2013), Battaïa et al. (2017).

The problem considered here is novel and more complex. The nearest problems to it with common elements are those of structural parametric optimization of machining processes in a transfer line of conveyor-type composed of machine tools reported by Levin and Tanaev (1978) and the line balancing problems with equipment selection considered in (Bukchin and Tzur 2000; Bukchin and Rubinovitz 2003). Levin and Tanaev (1978) studied the same type (as in this work) of transfer lines, but they considered processing only homogeneous parts. Also, the selection of an optimal aggregation from a set of feasible aggregation options was not considered in that work. Bukchin and Tzur (2000), Bukchin and Rubinovitz (2003) considered only the case where the intensities of operations execution were uniquely determined by the equipment option selected from a finite set, the possibility of the intersection of sets of operations was not studied. In this paper, the problem consists in selection of an optimal option of aggregation and rates of all operations minimizing the total batch processing cost while ensuring the required line productivity.

There are also our recent papers (Levin, Rozin and Dolgui 2012; Levin, Rozin and Dolgui 2014; Dolgui et al. 2016; Levin, Rozin and Dolgui 2016), where some models and methods for solving problems related to the optimization of execution rates of a collection of intersecting operation sets have already been proposed. But, in that studies the selection of the structure of a collection of intersecting operations and of respective pieces of equipment for their execution were not considered. Note that each of the problems considered in (Levin, Rozin and Dolgui 2012; Levin, Rozin and Dolgui 2014; Dolgui et al. 2016; Levin, Rozin and Dolgui 2016) is a special case of the problem studied in this paper. 
To summarize, some aspects of the considered problem were already studied in the above mentioned publications, but no one of these articles has addressed the problem as a whole.

\section{Statement of the problem and its mathematical model}

\subsection{Outline of a machining process and a transfer line}

A process of machining multiple parts at a multi-position single-flow transfer line with linearly ordered (working) positions is considered. The input sequence of machined parts is composed of cyclically repeated identical subsequences (batches) $\delta=\left\{\delta_{1}, \ldots, \delta_{n}\right\}$, including all parts of a given list $M$; some parts $d \in M$ in the batch $\delta$ can be repeated, i.e. $n \geq|M|$. Parts are machined successively one by one at each working position in the order of their arrival and location of the positions in the transfer line. At each position for each part a given set of machining operations are executed in parallel (simultaneously). The sets executed at the same position for different parts can intersect. It is assumed that the same operation for different parts is executed by the same tools, but some of its parameters (in particular, the working stroke, cutting lengths, etc.) for different parts can differ.

The process consists of takts of simultaneous machining all parts located at respective positions. At each time point only one part is disposed at each position. After completing the current takt, all processed parts are moved simultaneously to their next respective working position. The part from the terminal position leaves the line and the next one of the input sequence is loaded to the first position. Then the following takt is executed. The subsequence of $n$ takts that result in the production of one batch constitute the cycle of the batch processing. Without loss of generality, we assume that in takt 1 part $\delta_{1}$ of subsequence $\delta$ is located at position 1 . Then in the takt $i=1, \ldots, n$ in position $k=1,2, \ldots$ the part $d_{i k}=\delta_{\chi(i, k)}$ is processed, where $\chi(i, k)=1+\bmod ((n+i-\bmod (k, n)), n)$ is the index of this part in the batch $\delta$.

Subsequently, $J$ is the given set of all operations executed at all line positions for all parts and $J_{i}$ is the subset of the operations from $J$ executed in takt $i \in I=\{1, \ldots, i, \ldots, n\}$.

Table 1. Allocation of parts to positions in takts of a machining cycle

\begin{tabular}{|c|c|c|c|c|c|c|}
\hline & \multicolumn{7}{|c|}{ Positions } \\
\hline Takts & 1 & 2 & 3 & 4 & 5 & 6 \\
\hline 1 & $1 / 1$ & $6 / 4$ & $5 / 3$ & $4 / 3$ & $3 / 2$ & $2 / 1$ \\
\hline 2 & $2 / 1$ & $1 / 1$ & $6 / 4$ & $5 / 3$ & $4 / 3$ & $3 / 2$ \\
\hline 3 & $3 / 2$ & $2 / 1$ & $1 / 1$ & $6 / 4$ & $5 / 3$ & $4 / 3$ \\
\hline 4 & $4 / 3$ & $3 / 2$ & $2 / 1$ & $1 / 1$ & $6 / 4$ & $5 / 3$ \\
\hline 5 & $5 / 3$ & $4 / 3$ & $3 / 2$ & $2 / 1$ & $1 / 1$ & $6 / 4$ \\
\hline 6 & $6 / 4$ & $5 / 3$ & $4 / 3$ & $3 / 2$ & $2 / 1$ & $1 / 1$ \\
\hline
\end{tabular}


Figure 1 illustrates a layout of such a transfer line.

Table 1 presents an allocation of parts of the batch $\delta=(1,1,2,3,3,4)$ to the positions of a 6 -position transfer line in different takts of one cycle of machining (index of the part in the sequence $\delta /$ its type).

In general, identical operations may be executed at different positions and the set $I$ of takts of the cycle may include identical takts. However, to simplify the presentation, here all takts in a cycle and operations of different positions are considered as different, i.e. each operation $j \in J$ is executed at its own position $k(j)$. In this case, the takt $i \in I$ and the operation $j \in J_{i}$ determine the part $d_{i j}$ machined by this operation in this takt. This makes it possible to exclude subsequently from consideration the position indices in the variables.

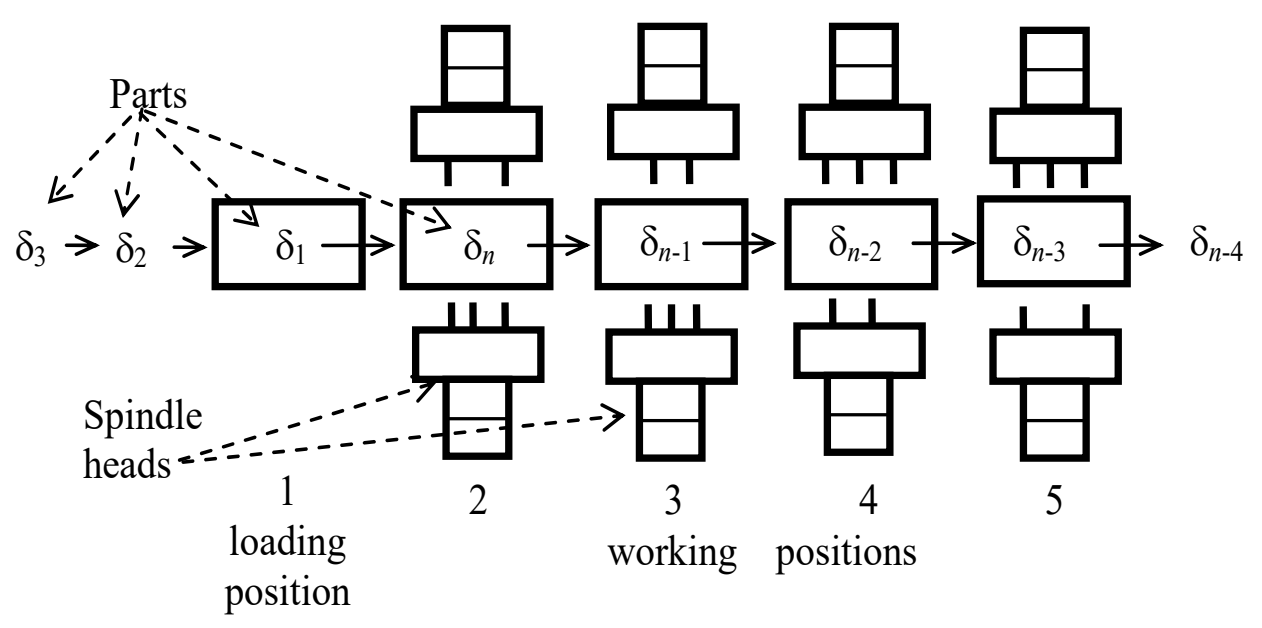

Figure 1. An example of part allocation in the first takt for the first 5 positions

In this paper, the case when the feed per minute of an operation is the same for all parts processed is considered.

The following notations are introduced (see in the Appendix the table with all notations):

- $L_{j d}$ is the given (minimal required) working stroke of the respective drive unit for operation $j \in J$ when machining part $d \in M, L_{j d}=0$ if operation $j$ is not executed for $d$;

- $\boldsymbol{S}_{j}=\left[S_{j 1}, S_{j 2}\right]$ is the given range of feed per minute $S_{j}$ for operation $j \in J$ considering that this operation is executed for different parts (value $S_{j}$ is to be determined).

At the design stage of a machining process and transfer line, some operations can be aggregated in blocks. All operations of a block are executed in parallel by the same drive unit (in particular with the use of a single multi-spindle head) with common feed per minute and working stroke. We study the case when (i) the possibilities of aggregation of operations $j \in J$ into blocks are specified by a family $W$ of non-unit nonintersecting subsets $w$ of operations from $J$, (ii) each subset $w \in W$ can be executed either completely aggregated (i.e. as one block) or completely disaggregated (i.e. as $|w|$ 
individual operations), (iii) any combination of aggregation/disaggregation option of potential blocks is possible.

Let $q_{w}=0$ if all operations from $w$ are executed in aggregate manner and $q_{w}=1$ otherwise. The requirement of a common feed per minute for all operations of the block excludes the possibility of selecting the best machining conditions for each of its operations individually. It is assumed that for $w \in W$ the common working stroke (for $q_{w}=0$ ) of all operations $j \in w$ when machining part $d$ is $L_{w d}=\max \left\{L_{j d} \mid j \in w\right\}$ and $\bigcap_{j \in w} \boldsymbol{S}_{j} \neq \varnothing$ because otherwise operations from $w$ cannot be executed in one block. Further, $\boldsymbol{q}=\left(q_{w} \mid w \in W\right)$ and $Q$ is the set of possible options of vector $\boldsymbol{q}$ to be selected, $|Q| \leq 2^{|W|}$.

The case when the selected aggregation option and the feed per minute for all operations remain invariable during the line functioning is considered.

An example of execution of two operations from a subset $w \in W$ for part $d \in M$ is shown in Figure 2a) for their disaggregated execution and in Figure 2b) for their aggregated option. In the first case the working strokes $L_{j_{1} d}, L_{j_{2} d}$ and feeds per minute $S_{j_{1}}, S_{j_{2}}$ for operations $j_{1}$ and $j_{2}$ are individual. In the second case, these operations have common working stroke $L_{w d}=\max \left\{L_{j d} \mid j \in w\right\}=$ $L_{j_{1} d}$ and a feed per minute $S_{w} \in \boldsymbol{S}_{j_{1}} \cap \boldsymbol{S}_{j_{2}}$.

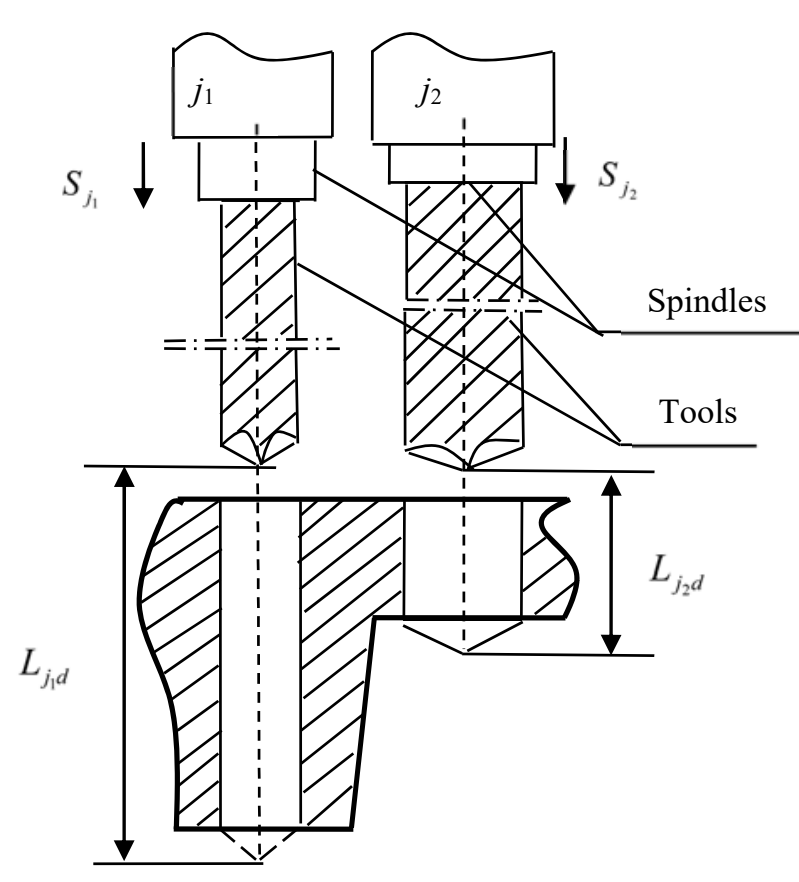

Part $d$

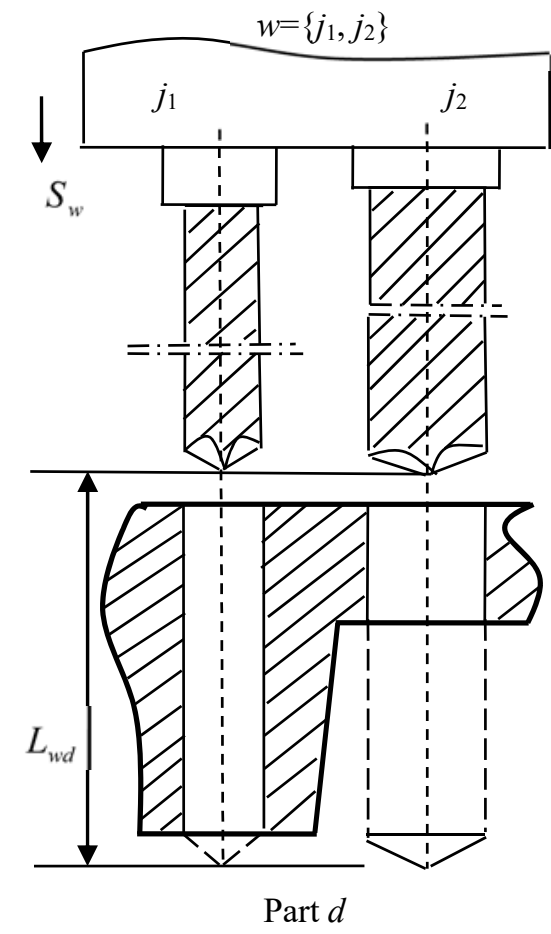

b)

Figure 2. Disaggregated (a) and aggregated $(b)$ execution of operations $j_{1}$ and $j_{2}$ 
It is assumed that operations of one position can be aggregated into several blocks and each block can comprise operations executed for different parts processed at respective position in different takts.

As was above mentioned, it is assumed that with an accuracy sufficient for considered stage of the manufacturing process design, the selected feed per minute of each operation allows to determine (for the accepted aggregation option) other components of its machining conditions. In turn, that makes it possible to estimate for each tool its average life time and consumption, for machining a single batch.

Decisions on how operations are aggregated into blocks as well as decisions on feeds per minute for each block are made at the line design stage and remain invariable (at least during a large period of its operating time). Therefore, the choice of the most rational joint decisions regarding these important characteristics of the structure and the parameters of the manufacturing process are crucial.

In the next subsection, the dependences of the components of productivity and the cost of the manufacturing process on the selected decisions are considered.

In the future, for the convenience of presentation of the proposed mathematical model of the considered problem and the methods for solving it, parameter $S_{j}$ of operation $j$ is substituted for parameter $u_{j}=1 / S_{j}$ which we will call "operation rate". It is obvious that $u_{j} \in U_{j}=\left[u_{j 1}, u_{j 2}\right]=\left[1 / S_{j 2}, 1 / S_{j 1}\right]$. As operation $j \in J$ in takt $i \in I$ is executed for part $d_{i j}$, value $L_{i j}=L_{j d_{i j}}$ will be considered as the "volume" of this operation in this takt. Operation rate means the time spent for execution of a unit of volume of this operation.

Since all operations $j$ from block $w \in W$ should have the same operation rate $u_{j}$ then $u_{j} \in \underline{\boldsymbol{U}}_{w}=$ $\left[\underline{U}_{1 w}=\max \left\{u_{1 j} j j \in w\right\}, \underline{U}_{2 w}=\min \left\{u_{2 j} j j \in w\right\}\right] \neq \varnothing$. For fixed $\boldsymbol{q} \in Q$ the sought vector $\boldsymbol{u}=\left(u_{j} j j \in J\right)$ must be selected from the set $\underline{\boldsymbol{U}}(\boldsymbol{q})=\left\{\boldsymbol{u} \in \boldsymbol{U} \mid u_{j^{\prime}}=u_{j^{\prime \prime}} \in \underline{\boldsymbol{U}}_{w}\right.$ for any $j^{\prime}, j^{\prime \prime} \in w$ and $w \in W$ if $\left.q_{w}=0\right\}$, where $\boldsymbol{U}=\prod_{j \in J} U_{j}$.

The following additional assumptions are used in this study:

1. Operations performed at different working positions of the line, as well as all takts of the cycle for processing a batch of parts, are considered as different.

2. The sets of operations of potential blocks do not intersect.

3. All operations of each of the potential blocks can be performed either completely aggregated (in the block) or completely disaggregated (individually), no possibility to aggregate only a part of block.

4. All operations aggregated in one block are performed with the same intensity.

It should be noted that the proposed methods do not need assumption 1 and can be applied without it, but the presentation of the mathematical model will be much complicated. The generalization of the rest of these assumptions requires additional research. 


\subsection{Cost and time of batch $\delta$ machining}

In the considered problem statement, the components of the total cost and total time for machining one batch $\delta$ for the fixed values of vectors $\boldsymbol{q} \in Q$ and $\boldsymbol{u} \in \boldsymbol{U}$ can be defined as follows.

Let $\Phi_{1}(\boldsymbol{q}, \boldsymbol{u})=\Phi_{11}(\boldsymbol{q}, \boldsymbol{u})+\Phi_{12}(\boldsymbol{q}, \boldsymbol{u})$ and $\Phi_{2}(\boldsymbol{q}, \boldsymbol{u})=\Phi_{21}(\boldsymbol{q}, \boldsymbol{u})+\Phi_{22}(\boldsymbol{q}, \boldsymbol{u})$ be the dependences of the total cost and the total time of one cycle of machining the batch $\delta$ on values of vectors $\boldsymbol{q}$ and $\boldsymbol{u}$ (which are decision variables).

The term $\Phi_{11}(\boldsymbol{q}, \boldsymbol{u})$ takes into account salary, depreciation of equipment, its maintenance cost, overheads, etc. The term $\Phi_{21}(\boldsymbol{q}, \boldsymbol{u})$ takes into account besides the operating time also the time for tools replacement, maintenance time, etc. In turn, the terms $\Phi_{12}(\boldsymbol{q}, \boldsymbol{u})$ and $\Phi_{22}(\boldsymbol{q}, \boldsymbol{u})$ take into account the cost and time related to the consumption of tools per one cycle of machining the batch $\delta$, respectively.

The terms $\Phi_{11}(\boldsymbol{q}, \boldsymbol{u})$ and $\Phi_{21}(\boldsymbol{q}, \boldsymbol{u})$ are considered usually as linearly dependent on the net duration of the cycle of machining the batch $\delta$ :

$$
\Phi_{p 1}(\boldsymbol{q}, \boldsymbol{u})=G_{p 0}(\boldsymbol{q})+G_{p 1}(\boldsymbol{q}) \sum_{i \in I}\left(\max \left\{L_{i j} u_{j} \mid j \in J_{i}\right\}+t_{b i}\right), p=1,2 .
$$

Here and below the $p=1$ refers to the cost and $p=2$ to the time.

In (1), $L_{i j} u_{j}$ is the duration of operation $j$ in takt $i$; $\max \left\{L_{i j} u_{j} \mid j \in J_{i}\right\}+t_{b i}$ is the net duration of takt $i ; \sum_{i \in I}\left(\max \left\{L_{i j} u_{j} \mid j \in J_{i}\right\}+t_{b i}\right)$ is the net duration of the cycle, where $t b i$ is the auxiliary time (e.g. the duration of idle movements); $G_{p 0}(\boldsymbol{q})$ are components of cost and time related to a single cycle of machining $\delta$ that do not depend on the cycle net duration.

Components $G_{11}(\boldsymbol{q})$ and $G_{21}(\boldsymbol{q})$ are values of respective cost and time per unit of the cycle net duration. Coefficients $G_{p l}(\boldsymbol{q})$ depend on the accepted option $\boldsymbol{q}$ of aggregation and are assumed to be given for all possible $\boldsymbol{q}, p=1,2, l=0,1$. Coefficients $G_{p 0}(\boldsymbol{q})$ allow to take into account in particular the situation when the production line is designed for a fixed output.

In many real-life situations, with a sufficient accuracy, the following form of these functions can be used:

$$
G_{p l}(\boldsymbol{q})=\underline{E}_{p \underline{l}}+\sum_{w \in W}\left(E_{p l w}\left(1-q_{w}\right)+e_{p l w} q_{w}\right),
$$

where $\underline{E}_{p l} \geq 0$ takes into account the piece of the cost (or time) that does not depend on aggregation of operations, $E_{p l w} \geq 0$ and $e_{p l w} \geq 0$ take into account the piece of the cost (or time) related to aggregated or disaggregated executing the operations of $w \in W$, respectively. Further it is assumed that $E_{p l w}<e_{p l w}$ for all $p=1,2, l=0,1$, and $w \in W$.

Let consider in more detail the terms $\Phi_{12}(\boldsymbol{q}, \boldsymbol{u})$ and $\Phi_{22}(\boldsymbol{q}, \boldsymbol{u})$. Note, that these terms depend mainly on rates $\boldsymbol{u}$, but the range $\underline{\boldsymbol{U}}(\boldsymbol{q})$ of possible values of vector $\boldsymbol{u}$ is determined by the selected 
values for $\boldsymbol{q}$. In this paper, when selecting $\boldsymbol{u} \in \underline{\boldsymbol{U}}(\boldsymbol{q})$, it is assumed that tools are replaced independently from each other as they wear. Note that an approach to optimize machining conditions under group replacement of tools was considered in (Levin and Rozin 2009).

Let $R_{j}$ be the set of tools executing operation $j \in J$ and $N_{i j r}\left(u_{j}\right)$ be the estimated number of parts $d_{i j}$ machined by this tool during its life time $T_{r d_{i j}}\left(u_{j}\right)$ under assumption that tool $r$ machines only the part $d_{i j}$. The value $N_{i j r}\left(u_{j}\right)=T_{r d_{i j}}\left(u_{j}\right) /\left(l_{j r d_{i j}} u_{j}\right)$, where $l_{j r d_{i j}}$ is the given machining length of machining part $d_{i j}$ by tool $r \in R_{j}$, and $l_{j r d_{i j}}=0$, if tool $r \in R_{j}$ does not machine part $d_{i j}$.

Under individual replacement of worn tools, the average number of cycles of batch $\delta$ machining between replacements of tool $r \in R_{j}$ is equal to $N_{j r}\left(u_{j}\right)=1 / \sum_{i \in I}\left(1 / N_{i j r}\left(u_{j}\right)\right)$.

To evaluating the dependence of tool life on the operation rate, we will introduce the following assumptions:

a) The feed per revolution $s_{j r}$ for tool $r \in R_{j}$ of operation $j$ is the same for all parts $d \in M$ it processes. This feed is usually maximized in the possible range (determined by the processing conditions of all the parts), taking into account its possible relations with the feeds of other tools for this operation. Therefore, to simplify it is assumed that the feeds $s_{j r}$ are known in advance for each tool $r \in R_{j}$ of each operation $j \in J$. Thus, the selected rate $u_{j}$ of operation $j$ determines the cutting speed $v_{j r d}$ when processing part $d$ by tool $r: v_{j r d}=\sigma_{j r d} / u_{j}$, where $\sigma_{j r d}$ is a given constant depending on the diameter of machining.

b) As in (Levin and Tanaev, 1978), the dependence of the expected tool life on feed and cutting speed can be presented by the following modification of the well-known Taylor function: $T_{r d}(s, v)=\min _{\mu=1, \ldots, \bar{\mu}_{r d}} \frac{\bar{C}_{r d \mu}}{S^{\eta_{r d \mu}} v^{\bar{\rho}_{r d \mu}}}$, where $\bar{\mu}_{r d}, \bar{C}_{r d \mu}>0$, и $\bar{\rho}_{r d \mu}>\eta_{r d \mu}>1$ are known constants for the specific processing conditions (material of the part, cutting depth, tool material, etc.), $r \in R_{j}, d \in M, \mu=1, \ldots$, $\bar{\mu}_{r d}$. This modification describes the considered dependence as a concave (in logarithmic scale) function that is in good agreement with the majority of real life situations for a wide range of feed and cutting speed changes.

In accordance with above mentioned, we obtain the following dependence of the tool life for tool $r$ when processing part $d_{i j}$ with operation rate $u_{j}$ (for the simplicity indexes $i j$ for the part $d_{i j}$ are omitted):

$$
T_{r d}\left(u_{j}\right)=\min _{\mu=1, \ldots, \bar{\mu}_{r d}} \widetilde{C}_{r d \mu} u_{j}^{\bar{\rho}_{r d \mu}}
$$


where $\widetilde{C}_{r d \mu}=\frac{\bar{C}_{r d \mu}}{S^{\eta_{r d \mu}} \bar{\sigma}^{\bar{\rho}_{r d \mu}}}>0$.

Hence, cost and time of operation $j$ in takt $i$ (i.e. when machining the part $d_{i j}$ ) related to the consumption of tools per one cycle of machining the batch $\delta$ for a fixed $u_{j} \in U_{j}$ are equal to:

$$
f_{p i j}\left(u_{j}\right)=\sum_{r \in R_{j}} g_{p j r} / N_{i j r}\left(u_{j}\right)=\sum_{r \in R_{j}} \max _{\mu=1, \ldots, \bar{\mu}_{r d}}\left(C_{p i j r \mu} / u_{j}^{\rho_{i j r \mu}}\right), p=1,2, i \in I, j \in J_{i},
$$

where $g_{p j r}$ is a given cost $(p=1)$ or a given time $(p=2)$ spent on one replacement of tool $r \in R_{j}$, $C_{p i j r \mu}=g_{p j r} l_{r d_{i j}} / \widetilde{C}_{r d_{i j} \mu}, \rho_{i j r \mu}=\bar{\rho}_{r d_{i j} \mu}-1$. It is obvious that functions $f_{p i j}\left(u_{j}\right), p=1,2$ are positive nonincreasing convex functions of operation rate $u_{j} \in U_{j}$. According to above mentioned, $f_{p i j}\left(u_{j}\right)=0$ if operation $j$ is not executed in takt $i$.

Thereby for fixed values of vectors $\boldsymbol{q} \in Q$ and $\boldsymbol{u} \in \underline{\boldsymbol{U}}(\boldsymbol{q})$ the cost $\Phi_{12}(\boldsymbol{q}, \boldsymbol{u})$ and the time $\Phi_{22}(\boldsymbol{q}, \boldsymbol{u})$ are defined by the following relations:

$$
\Phi_{p 2}(\boldsymbol{q}, \boldsymbol{u})=\sum_{i \in I} \sum_{j \in J_{i}} f_{p i j}\left(u_{j}\right), p=1,2 .
$$

Thus, the total cost and total time for machining one batch $\delta$ of parts are defined by the expressions:

$$
\Phi_{p}(\boldsymbol{q}, \boldsymbol{u})=G_{p 0}(\boldsymbol{q})+G_{p 1}(\boldsymbol{q}) \sum_{i \in I} \cdot\left(\max \left\{L_{j d_{i j}} u_{j} j j \in J_{i}\right\}+t_{b i}\right)+\sum_{i \in I} \sum_{j \in J_{i}} f_{p i j}\left(u_{j}\right), p=1,2 .
$$

\subsection{Mathematical model of the problem}

The considered problem is to determine an aggregation option $\boldsymbol{q} \in Q$ for operations from $w \in W$ and operation rates $\boldsymbol{u}=\left(u_{j} j \in J\right) \in \underline{\boldsymbol{U}}(\boldsymbol{q})$ to minimize the total cost $\Phi_{1}(\boldsymbol{q}, \boldsymbol{u})$ of one cycle of batch $\delta$ machining, provided that the total time $\Phi_{2}(\boldsymbol{q}, \boldsymbol{u})$ of the cycle (including the time spent on equipment maintenance and worn tools replacement) does not exceed the specified value $T^{0}$ determined on the basis of the required line throughput. Taking into account the proposed assumptions, this problem is reduced to the following mixed integer nonlinear programming problem:

$$
\text { Minimize } \Phi_{1}(\mathbf{q}, \mathbf{u})=G_{10}(\mathbf{q})+G_{11}(\mathbf{q}) \sum_{i \in I}\left(\max \left\{L_{i j} u_{j} \mid j \in J_{i}\right\}+t_{b i}\right)+\sum_{i \in I} \sum_{j \in J_{i}} f_{1 i j}\left(u_{j}\right),
$$

s.t.

$$
\begin{aligned}
& \Phi_{2}(\boldsymbol{q}, \boldsymbol{u})=G_{20}(\boldsymbol{q})+G_{21}(\boldsymbol{q}) \sum_{i \in I}\left(\max \left\{L_{i j} u_{j} \mid j \in J_{i}\right\}+t_{b i}\right)+\sum_{i \in I} \sum_{j \in J_{i}} f_{2 i j}\left(u_{j}\right) \leq T^{0}, \\
& \boldsymbol{q} \in Q, \\
& \boldsymbol{u} \in \underline{\boldsymbol{U}}(\boldsymbol{q}),
\end{aligned}
$$

where $\boldsymbol{q}=\left(q_{w} \mid w \in W\right), \boldsymbol{u}=\left(u_{j} \mid j \in J\right)$ are decision variables. 
In the next section, a special method to solve the problem (6) - (9), called further as Problem $\mathbf{A}$, is proposed.

\section{Solution technique}

The considered approach to solve Problem $\mathbf{A}$ is based on the following its properties:

i) the variables of the problem are divided into two heterogeneous groups: $|W|$-dimensional binary vector $\boldsymbol{q}=\left(q_{w} \mid w \in W\right) \in Q$ and $|J|$-dimensional vector $\boldsymbol{u}=\left(u_{j} \mid j \in J\right) \in \boldsymbol{U}$ with continuous components $u_{j} \in U_{j}$;

ii) functions $\Phi_{1}(\boldsymbol{q}, \boldsymbol{u})$ and $\Phi_{2}(\boldsymbol{q}, \boldsymbol{u})$ have identical structure;

iii) if $\boldsymbol{q}^{\prime}, \boldsymbol{q}^{\prime \prime} \in Q$ are such that $\boldsymbol{q}^{\prime} \neq \boldsymbol{q}^{\prime \prime}$ and $q^{\prime}{ }_{w} \leq q^{\prime \prime}{ }_{w}$ for all $w \in W$ then $\underline{\boldsymbol{U}}\left(\boldsymbol{q}^{\prime}\right) \subseteq \underline{\boldsymbol{U}}\left(\boldsymbol{q}^{\prime \prime}\right)$ and $\Phi_{p}\left(\boldsymbol{q}^{\prime}, \boldsymbol{u}\right)<$ $\Phi_{p}\left(\boldsymbol{q}^{\prime \prime}, \boldsymbol{u}\right)$ for all $\boldsymbol{u} \in \underline{\boldsymbol{U}}\left(\boldsymbol{q}^{\prime}\right), p=1,2$;

iv) under the previous conditions iii), if $G_{p l}\left(\boldsymbol{q}^{\prime}\right)=G_{p}\left(\boldsymbol{q}^{\prime \prime}\right)$ for all $p=1,2, \quad l=0,1$, then $\Phi_{p}\left(\boldsymbol{q}^{\prime}, \boldsymbol{u}^{*}\left(\boldsymbol{q}^{\prime}\right)\right) \geq \Phi_{p}\left(\boldsymbol{q}^{\prime}, \boldsymbol{u}^{*}\left(\boldsymbol{q}^{\prime \prime}\right)\right), p=1,2$, where $\boldsymbol{u}^{*}(\boldsymbol{q})$ is the solution of Problem $\mathbf{A}$ for a fixed $\boldsymbol{q}$.

\subsection{Two-level decomposition scheme}

The two-level decomposition scheme proposed to solve Problem A is depicted in Figure 3.

At the lower level, for a fixed vector $\boldsymbol{q} \in Q$, the corresponding sub-problem $\mathbf{B}(\boldsymbol{q})$ is solved. A subproblem $\mathbf{B}(\boldsymbol{q})$ consists in determining the value $\boldsymbol{u}^{*}(\boldsymbol{q})$ of vector $\boldsymbol{u} \in \underline{U}(\boldsymbol{q})$ minimizing the function $\Theta_{1}(\boldsymbol{q}, \boldsymbol{u})=$ $G_{11}(\boldsymbol{q}) \sum_{i \in I}\left(\max \left\{L_{i j} u_{j} \mid j \in J_{i}\right\}+t_{b i}\right)+\sum_{i \in I} \sum_{j \in J_{i}} f_{1 i j}\left(u_{j}\right)$ subject to the condition:

$$
\Theta_{2}(\boldsymbol{q}, \boldsymbol{u})=G_{21}(\boldsymbol{q}) \sum_{i \in I}\left(\max \left\{L_{i j} u_{j} \mid j \in J_{i}\right\}+t_{b i}\right)+\sum_{i \in I} \sum_{j \in J_{i}} f_{2 i j}\left(u_{j}\right) \leq T^{0}-G_{20}(\boldsymbol{q}) .
$$

At the upper level, sub-problem $\mathbf{C}$ to define the vector $\boldsymbol{q}^{*}$ minimizing the function $\Theta^{*}(\boldsymbol{q})+G_{10}(\boldsymbol{q})$ is solved, where $\Theta^{*}(\boldsymbol{q})=\Theta_{1}\left(\boldsymbol{q}, \boldsymbol{u}^{*}(\boldsymbol{q})\right)$ and $\Theta^{*}(\boldsymbol{q})=\infty$ if sub-problem $\mathbf{B}(\boldsymbol{q})$ is unsolvable.

$$
\begin{aligned}
& \text { C: } \Theta^{*}(\boldsymbol{q})+G_{10}(\boldsymbol{q}) \rightarrow \min , \\
& \boldsymbol{q} \in Q . \\
& \begin{array}{|l|l|}
\hline \boldsymbol{q} & \boldsymbol{q} \\
\hline
\end{array} \\
& \mathbf{B}(\boldsymbol{q}): \quad \Theta_{1}(\boldsymbol{q}, \boldsymbol{u}) \rightarrow \min \left(=\Theta^{*}(\boldsymbol{q})\right), \\
& \Theta_{2}(\boldsymbol{q}, \boldsymbol{u}) \leq T^{0}-G_{20}(\boldsymbol{q}) \text {, } \\
& \boldsymbol{u} \in \underline{\boldsymbol{U}}(\boldsymbol{q}), \boldsymbol{q}=\text { const. }
\end{aligned}
$$

Figure 3. Decomposition scheme to solve Problem A 
Since $\boldsymbol{q}^{*}$ and $\boldsymbol{u}^{*}(\boldsymbol{q})$ are solutions of sub-problems $\mathbf{C}$ and $\mathbf{B}(\boldsymbol{q})$ respectively, then $\left(\boldsymbol{q}^{*}, \boldsymbol{u}^{*}\right)=\left(\boldsymbol{q}^{*}, \boldsymbol{u}^{*}\left(\boldsymbol{q}^{*}\right)\right)$ is a solution of Problem A. If $\boldsymbol{q}^{*}$ and $\boldsymbol{u}^{*}\left(\boldsymbol{q}^{*}\right)$ are approximate solutions of corresponding sub-problems, then vector $\left(\boldsymbol{q}^{*}, \boldsymbol{u}^{*}\right)$ is an approximate solution of Problem $\mathbf{A}$.

Below some of possible approaches to solve the obtained sub-problems are presented. For a more detailed consideration of sub-problems $\mathbf{B}(\boldsymbol{q})$ of the lower level, it is necessary to consider if the corresponding operations (and variables associated with them) are executed in the aggregate or disaggregate manner. Since for aggregated execution of some block $w$, operation rates $u_{j}$ for all operations $j \in w$ are the same, then the number of variables of sub-problem $\mathbf{B}(\boldsymbol{q})$ can be reduced. For this, the following additional notations are introduced:

$W^{0}(\boldsymbol{q})=\left\{w \in W \mid q_{w}=0\right\}$ is a subset of operation blocks from $W$ executed in the aggregate manner for a fixed $\boldsymbol{q} \in Q$;

$W_{i}^{0}(\boldsymbol{q})=\left\{w \in W^{0}(\boldsymbol{q}) \mid w \cap J_{i} \neq \varnothing\right\}$ is a subset of operation blocks from $W^{0}(\boldsymbol{q})$ that comprise operations executed in takt $i \in I$;

$J^{1}(\boldsymbol{q})=\left\{j \in J \mid j \notin w \in W^{0}(\boldsymbol{q})\right\}$ is a subset of operations from $J$ that are executed for a fixed $\boldsymbol{q}$ in the disaggregate manner (i.e. with individual rates);

$\boldsymbol{u}(\boldsymbol{q})=\left(u_{j} j \in J^{1}(\boldsymbol{q})\right)$ and $\underline{\boldsymbol{u}}(\boldsymbol{q})=\left(\underline{u}_{w} \mid w \in W^{0}(\boldsymbol{q})\right)$ are vectors of operation rates to be determined for operations $j$ from $J^{1}(\boldsymbol{q})$ and for operations $j$ from $w \in W^{0}(\boldsymbol{q})$ respectively;

$\Lambda_{i w}=\max \left\{L_{i j} j j \in J_{i \cap w}\right\}$ is the volume of potential operation block $w \in W$ executed in $i \in I$;

$\widetilde{f}_{p j}\left(u_{j}\right)=\sum_{i \in I} f_{p i j}\left(u_{j}\right)$ and $\hat{f}_{p w}\left(\underline{u}_{w}\right)=\sum_{j \in w} \widetilde{f}_{p j}\left(\underline{u}_{w}\right)$ are the functions of cumulative cost $(p=1)$ and of cumulative time $(p=2)$ for operation $j \in J$ and for operation block $w \in W$, respectively, on their rates in a single execution of one cycle of batch machining;

$\widetilde{E}_{p}(\boldsymbol{q})=\underline{E}_{p 1}+\sum_{w \in W^{0}(\boldsymbol{q})} E_{p 1 w}+\sum_{w \in W \backslash W^{0}(\boldsymbol{q})} e_{p 1 w}$ is the cost $(p=1)$ or the time $(p=2)$ of maintenance of equipment and its depreciation per unit of cycle duration.

Then, for a fixed vector $\boldsymbol{q} \in Q$, sub-problem $\mathbf{B}(\boldsymbol{q})$ of the lower level is reduced to the following nonlinear programming problem:

$$
\begin{aligned}
\operatorname{Minimize} \widetilde{\Theta}_{1}(\boldsymbol{u}(\boldsymbol{q}), \underline{\boldsymbol{u}}(\boldsymbol{q}))= & \widetilde{E}_{1}(\boldsymbol{q}) \sum_{i \in I}\left(\max \left\{\max \left\{L_{i j} u_{j} \mid j \in J_{i}^{1}(\boldsymbol{q})\right\}, \max \left\{\Lambda_{i w} \underline{u}_{w} \mid w \in W_{i}^{0}(\boldsymbol{q})\right\}\right\}+t_{b i}\right) \\
& +\sum_{j \in J^{1}(\mathbf{q})} \widetilde{f}_{1 j}\left(u_{j}\right)+\sum_{w \in W^{0}(\mathbf{q})} \hat{f}_{1 w}\left(\underline{u}_{w}\right)
\end{aligned}
$$

s.t.

$$
\widetilde{\Theta}_{2}(\boldsymbol{u}(\boldsymbol{q}), \underline{\boldsymbol{u}}(\boldsymbol{q}))=\widetilde{E}_{2}(\boldsymbol{q}) \sum_{i \in I}\left(\max \left\{\max \left\{L_{i j} u_{j} \mid j \in J_{i}^{1}(\boldsymbol{q})\right\}, \max \left\{\Lambda_{i w} \underline{u}_{w} \mid w \in W_{i}^{0}(\boldsymbol{q})\right\}\right\}+t_{b i}\right)
$$




$$
+\sum_{j \in J^{1}(\boldsymbol{q})} \widetilde{f}_{2 j}\left(u_{j}\right)+\sum_{w \in W^{0}(\boldsymbol{q})} \hat{f}_{2 w}\left(u_{w}\right) \leq T^{0}
$$

$$
\begin{aligned}
& u_{j} \in U_{j}, \quad j \in J^{1}(\boldsymbol{q}), \\
& \underline{u}_{w} \in \underline{\boldsymbol{U}}_{w}, \quad w \in W^{0}(\boldsymbol{q}),
\end{aligned}
$$

where $u_{j}, j \in J^{1}(\boldsymbol{q}), \underline{u}_{w}, w \in W^{0}(\boldsymbol{q})$ are decision variables for the fixed vector $\boldsymbol{q}$.

According to the mentioned above property iii) of Problem A, the vector $\boldsymbol{u}^{*}\left(\boldsymbol{q}^{\prime}\right)$ can be used as an initial point in solving sub-problem $\mathbf{B}\left(\boldsymbol{q}^{\prime \prime}\right)$ if $\boldsymbol{q}^{\prime \prime} \geq \boldsymbol{q}^{\prime}$. Possible approaches to solve sub-problem $\mathbf{B}(\boldsymbol{q})$ is largely dependent on the properties of its components. In Dolgui et al. (2016), a special case of Problem A is studied when: (i) volumes $L_{i j}$ for any operation $j \in J$ are the same for all $i \in I_{j}$, where $I_{j}$ is the set of takts from $I$ in which operation $j$ is executed, (ii) values $\Lambda_{i w}$ for each operation block $w \in W$ are identical for all takts $i \in I(w)=\left\{i \in I \mid w \cap J_{i} \neq \varnothing\right\}$. In this case, the duration of operation $j \in J$ as well as the duration of operation block $w \in W$ are also the same for all takts $i \in I_{j}$ and $i \in I(w)$, respectively. The proposed approach to this problem is based on a combination of Lagrangian relaxation and Dynamic programming.

Below we will describe the approach to solve $\mathbf{B}(\boldsymbol{q})$ for more frequent case in practice when these volumes can be different.

\subsection{Sub-problem $B(q)$}

As above mentioned, in sub-problem $\mathbf{B}(\boldsymbol{q})$ functions $\tilde{f}_{p j}\left(u_{j}\right)$ and $\hat{f}_{p w}\left(\underline{u}_{w}\right)$ are non-increasing positive and convex on segments $U_{j}$ and $\underline{\boldsymbol{U}}_{w}$ respectively for all $j \in J, w \in W$. Therefore, the wellknown methods of convex programming are applicable to solve this sub-problem. Furthermore, the last two terms in the functions $\widetilde{\Theta}_{1}(\boldsymbol{u}(\boldsymbol{q}), \underline{\boldsymbol{u}}(\boldsymbol{q}))$ и $\widetilde{\Theta}_{2}(\boldsymbol{u}(\boldsymbol{q}), \underline{\boldsymbol{u}}(\boldsymbol{q}))$ are separable. Thus, to solve $\mathbf{B}(\boldsymbol{q})$ it is possible to use, in particular, an approach analogous to the one proposed in (Rozin, Levin, and Dolgui 2013; Levin, Rozin, and Dolgui 2014) which proved to be effective for a similar problem.

This approach is based on approximation of sub-problem $\mathbf{B}(\boldsymbol{q})$ by a linear programming problem.

To describe this approach let us introduce the following piecewise linear approximations of functions $\widetilde{f}_{p j}\left(u_{j}\right)$ and $\hat{f}_{p w}\left(\underline{u}_{w}\right)$ on the segments $U_{j}$ and $\underline{U}_{w}$, respectively:

$$
\begin{aligned}
& \tilde{f}_{p j}\left(u_{j}\right) \approx \max \left\{a_{p j k} u_{j}+b_{p j k} \mid k=1, \ldots, k_{1 p j}\right\}, p=1,2, j \in J, \\
& \hat{f}_{p w}\left(\underline{u}_{w}\right) \approx \max \left\{c_{p w k} \underline{u}_{w}+d_{p w k} \mid k=1, \ldots, k_{2 p w}\right\}, p=1,2, w \in W,
\end{aligned}
$$

where $a_{p j k}, b_{p j k}, c_{p w k}, d_{p w k}, k_{1 p j}$ and $k_{2 p w}$ are parameters of this approximation. Note that these 
parameters do not depend on the value of vector $\boldsymbol{q}$. Thus these approximations can be constructed in advance before the solution of Problem $\mathbf{A}$ and can be used to solve problems $\mathbf{B}(\boldsymbol{q})$ for different values of vector $\boldsymbol{q}$.

Then the approximate solution of problem $\mathbf{B}(\boldsymbol{q})$ for a fixed $\boldsymbol{q} \in Q$ can be obtained by solving the following linear programming problem:

$$
\begin{aligned}
& \text { Minimize } \sum_{i \in I} \widetilde{E}_{1}(\mathbf{q}) t_{i}+\sum_{j \in J^{1}(\mathbf{q})} y_{1 j}+\sum_{w \in W^{0}(\mathbf{q})} z_{1 w}, \\
& \sum_{i \in I} \widetilde{E}_{2}(\boldsymbol{q}) t_{i}+\sum_{j \in J^{1}(\boldsymbol{q})} y_{2 j}+\sum_{w \in W^{0}(\boldsymbol{q})} z_{2 w} \leq T^{0}, \\
& t_{i}-L_{i j} u_{j} \geq 0, \quad i \in I, \quad j \in J_{i}^{1}(\boldsymbol{q}), \\
& t_{i}-\Lambda_{i w} \underline{\boldsymbol{u}}_{w} \geq 0, \quad i \in I, w \in W_{i}^{0}(\boldsymbol{q}), \\
& y_{p j}-a_{p j k} u_{j} \geq b_{p j k}, p=1,2, j \in J^{1}(\boldsymbol{q}), k=1, \ldots, k_{1 p j}, \\
& z_{p w}-c_{p w k} \underline{u}_{w} \geq d_{p w k}, p=1,2, w \in W^{0}(\boldsymbol{q}), k=1, \ldots, k 2 p w, \\
& u_{j} \in U_{j}, \quad j \in J^{1}(\boldsymbol{q}), \\
& \underline{u}_{w} \in \underline{\boldsymbol{U}}_{w}, \quad w \in W^{0}(\boldsymbol{q}) .
\end{aligned}
$$

In this problem, vectors $t=\left(t_{i} \mid i \in I\right), y(\boldsymbol{q})=\left(y_{p j} \mid p=1,2, j \in J^{1}(\boldsymbol{q})\right), z(\boldsymbol{q})=\left(z_{p w} \mid p=1,2, w \in W^{0}(\boldsymbol{q})\right), \boldsymbol{u}(\boldsymbol{q})$ and $\underline{\boldsymbol{u}}(\boldsymbol{q})$ are to be defined. If $\left(t^{*}, y^{*}(\boldsymbol{q}), z^{*}(\boldsymbol{q}), \boldsymbol{u}^{*}(\boldsymbol{q}), \underline{\boldsymbol{u}}^{*}(\boldsymbol{q})\right)$ is its solution then vector $\boldsymbol{u}=(u j j j \in J)$ with the components $u_{j}=u_{j}^{*}(\boldsymbol{q})$ for $j \in J^{1}(\boldsymbol{q})$ and $u_{j}=\underline{u}_{w}^{*}(\boldsymbol{q})$ for $j \in w \in W^{0}(\boldsymbol{q})$ can be accepted as an approximate solution $\boldsymbol{u}^{*}(\boldsymbol{q})$ of problem $\mathbf{B}(\boldsymbol{q})$. The discrepancy between the minimum values of the objective functions of problem $\mathbf{B}(\boldsymbol{q})$ and its approximation (16)-(23) is determined by the accuracy of the approximation (14)-(15) of functions $\widetilde{f}_{p j}\left(u_{j}\right)$ and $\hat{f}_{p w}\left(\underline{u}_{w}\right)$ in the vicinity of solution of problem $\mathbf{B}(\boldsymbol{q})$.

To solve the approximate problem (16)-(23) for fixed values $\boldsymbol{q} \in Q$, the existing software tools such as CPLEX or LPSolve can be used. The performance of the proposed approach when solving a subproblem B( $\boldsymbol{q})$ using computer Intel Xeon CPU E5320 with parameters $1.86 \mathrm{GHz}$ and 8GB of RAM and the software LPSolve is reported in (Levin, Rozin and Dolgui 2016).

\subsection{Sub-problem $C$}

In sub-problem $\mathbf{C}$, the number of possible values of vector $\boldsymbol{q}$ in the set $Q$ may be up to $2^{|W|}$, so full enumeration of set $Q$ with solving of sub-problem $\mathbf{B}(\boldsymbol{q})$ for each $\boldsymbol{q} \in Q$ requires a significant time even for relatively small values of $|W|$ and practically impossible for a large $|W|$. In such a situation, it seems promising to use methods based on the ideas of random search, heuristics and metaheuristics 
in combination with the proposed below a special version of the method of sequential fixing of variables (MSFV).

The algorithm MSFV starts with initial value $\boldsymbol{q}^{0}$ of vector $\boldsymbol{q}$ obtained using some heuristic approach. This algorithm forms a sequence of vectors from $Q$, such that each subsequent vector differs from the previous vector by exactly one of its components. The components which values have been changed are considered as fixed and are not altered subsequently. The selection of the next vector of the sequence at the current iteration is performed as follows. For the current vector $\boldsymbol{q}^{c}$, the subset $Q\left(\boldsymbol{q}^{c}\right) \subset Q$ of vectors that differ from $\boldsymbol{q}^{c}$ by one of its non-fixed components is constructed. For each vector $\boldsymbol{q} \in Q\left(\boldsymbol{q}^{c}\right)$, sub-problem $\mathbf{B}(\boldsymbol{q})$ is solved. As the next vector of the sequence, the vector $\boldsymbol{q}^{\prime} \in Q\left(\boldsymbol{q}^{c}\right)$ that corresponds to the minimal value of the function $H(\boldsymbol{q})=\Theta^{*}(\boldsymbol{q})+G_{10}(\boldsymbol{q})$ in these subproblems is selected. The component by which vectors $\boldsymbol{q}^{\prime}$ and $\boldsymbol{q}^{c}$ differ is considered as fixed. The number of vectors in subsets $Q\left(\boldsymbol{q}^{c}\right)$ from iteration to iteration decreases from $|W|$ to 1 . Accordingly, the number of sub-problems $\mathbf{B}(\boldsymbol{q})$ to be solved is also reduced. At each iteration we get (in general) a new improved vector $\boldsymbol{q} \in Q$. The algorithm terminates when either the value of $H\left(\boldsymbol{q}^{c}\right)$ is not decreased, or the subset $Q\left(\boldsymbol{q}^{c}\right)=\varnothing$. The obtained value of $\boldsymbol{q}^{c}$ is taken as the solution of problem $\mathbf{C}$. The total number of sub-problems $\mathbf{B}(\boldsymbol{q})$ to be solved for calculation of function $H(\boldsymbol{q})$ for different $\boldsymbol{q}$ does not exceed $0.5\left(|W|^{2}+|W|\right)$.

Below the scheme of the algorithm MSFV is presented, where:

- $\Psi$ is a set of $w \in W$ with fixed values of component $\boldsymbol{q}_{w}$ for current vector $\boldsymbol{q}^{c}$;

- $\underline{\boldsymbol{q}}(\boldsymbol{q}, w)$ is a vector from $Q$ that differs from vector $\boldsymbol{q} \in Q$ only by the component $q_{w}$.

\section{Algorithm MSFV:}

Step 0. Assign $\boldsymbol{q}^{c} \leftarrow \boldsymbol{q}^{0}, Y^{c} \leftarrow H\left(\boldsymbol{q}^{0}\right), \Psi \leftarrow \varnothing$.

Step 1 . If $\Psi=W$ then $\boldsymbol{q}^{c}$ is a new solution of problem C. Else

Step 2. Find $w^{*}=\operatorname{argmin}\{H(\boldsymbol{q}(\boldsymbol{q}, w)) \mid w \in W \backslash \Psi\}$. If $Y^{c} \leq Y^{*}=H\left(\boldsymbol{q}\left(\boldsymbol{q}, w^{*}\right)\right)$ then assign $\Psi=W$ and go to Step 1. Else assign $\boldsymbol{q}^{c}=\underline{\boldsymbol{q}}\left(\boldsymbol{q}, w^{*}\right), Y^{c}=Y^{*}, \Psi=\Psi\left\{w^{*}\right\}$ and Step 2 is repeated.

The algorithm MSFV can be repeated with a new initial value $\boldsymbol{q}^{0}$. As such a value, in particular, the current solution obtained earlier can be used. The described algorithm MSFV can be evolved by means of selection at each iteration simultaneously several perspective components of current vector $\boldsymbol{q}$ for their fixing accordingly to the values of function $H(\boldsymbol{q})$ obtained.

A real life example of the design Problem A is considered in Section 5. 


\section{Industrial example}

\subsection{Input data}

As an illustrative example, we present here a fragment of machining process for a family $M=\{1,2,3,4\}$ of parts processed at a 6-position rotary transfer machine which is a part of a transfer line. This fragment considers the features (faces and holes) of parts from $M$ located at one side of each of these items. The family $M$ of parts and their features to be machined at this machine are depicted in Figure 4 . The dimensions of these features are given in Table 2. The material of all parts is gray cast iron with $\mathrm{HB}=190$.

The parts are machined one by one by sequentially repeated identical subsequences (batches). A batch $\delta=(1,1,2,3,3,4)$ is composed of 6 parts: two items of part 1 , one item of part 2 , two items of part 3 and one item of part 4 . The machining the considered features of the parts includes: rough and finish milling for faces 1 and 2, drilling and core drilling for holes 3-7, and spotfacing for all holes with the exception of holes 6 .

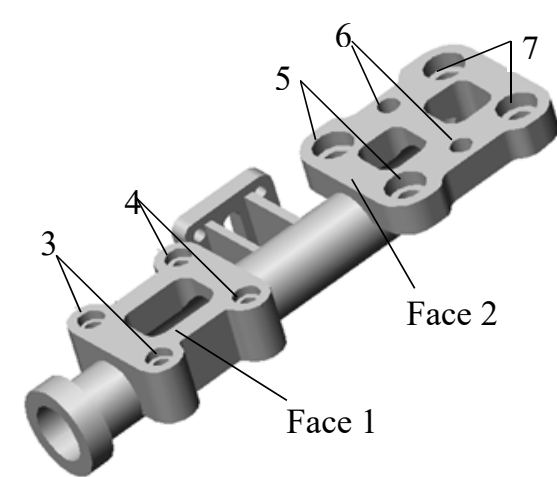

a) Part 1

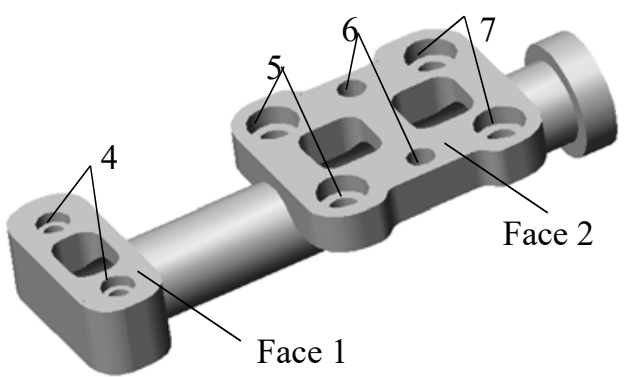

c) Part 3

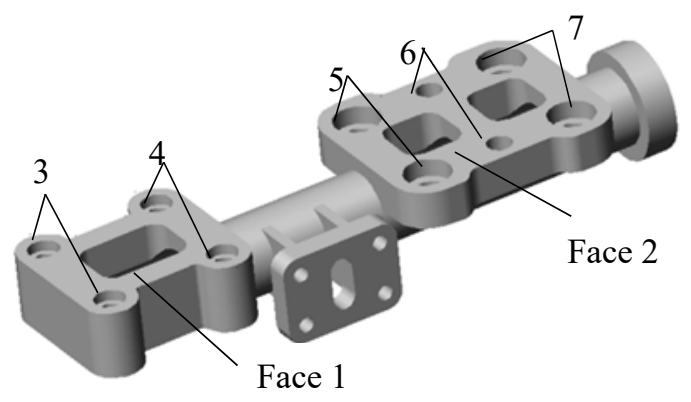

b) Part 2

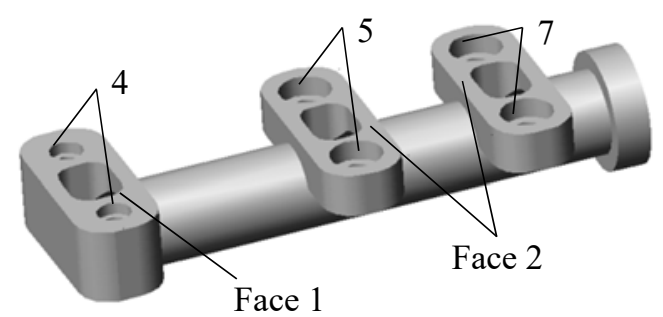

d) Part 4

Figure 4. The family of parts to be machined

The first position of the rotary machine is used only for loading and unloading of machined parts, others are working positions. Rough and finish milling are executed in the second and third position respectively by the face cutters mounted on a vertical milling head. In positions 4 to 6 , the drilling, spotfacing and core drilling are executed by the respective horizontal spindle heads. In the considered 
case the cycle of machining one batch $\delta$ consists of 6 takts and therefore the fixture of each part can be assigned to its own position of the rotary table. The allocation of parts to working positions in each takt of the cycle is presented in Table 1 . The time $t_{b i}$ of table movements (idle time) in each takt is equal to $0.2 \mathrm{~min}$.

The parts are installed on the positions so that the maximum number of machining steps for different parts could be carried out by the same tool. Machining steps are combined in operations (in terms of Section 3) so that each operation is executed by one spindle head. Since the material of all parts is the same we accept that the feed per revolution $s j r$, the range $\left[v_{1 j r}, v_{2 j r}\right]$ of possible values of cutting speed $v_{j r}$ as well as parameters of life time in the relation (2) for each tool $r$ are the same for all machined parts. For simplicity, we assume that $\bar{\mu}_{r d}=1$ for all tools and all parts. Feed per revolution $s_{j r}$ and range $\left[v_{1 j r}, v_{2 j r}\right]$ determine the ranges $U_{j}=\left[u_{1 j}, u_{2 j}\right]$ of possible values of rates $u_{j}$ of operations. Thus, in the relations (3) values $\rho_{i j r}$ are the same for all $r \in R_{j}$ and equal to $\rho_{i j}$ :

$$
f_{p i j}\left(u_{j}\right)=C_{p i j}^{\prime} u_{j}^{-\rho_{i j}},
$$

where $C_{p i j}^{\prime}=\sum_{r \in R_{j}} C_{p i j r}$.

Input data for machining process design are given in Table 2. These data include: operations executed at each position for each part; tools and their parameters; parameters of relation (2) for respective machining steps; cost and time spent for replacement of each tool. In Table 2, the following notation are used:

- $L_{j r d}, l_{j r d}, t_{j r d}, B_{j r d}$ are the working stroke, the cutting length, the depth of cut and the machining width for tool $r$ in operation $j$ when machining part $d$, respectively;

- $D_{j r}, z_{j r}$ and $s_{j r}$ are the diameter, the number of teeth (for cutter) and the feed per revolution of tool $r$ in operation $j$, respectively;

$-u_{1 j}, u_{2 j}$ are the lower and upper bounds of the range for the rate of operation $j$;

- $v_{1 j} r, v_{2 j}$ are the lower and upper bounds of the range of cutting speed for tool $r$ in operation $j$;

- $\widetilde{C}_{r d}, \bar{\rho}_{r d}$ are the parameters in the relation (2) for tool $r$ when machining part $d$;

- $g_{1 r}, g_{2 r}$ are the cost and time spent on one replacement of tool $r$. 

Table 2. Parameters of part features, tools, machining steps, tool life relations and structure of operations.

\begin{tabular}{|c|c|c|c|c|c|c|c|c|c|c|c|c|c|c|c|c|c|c|c|}
\hline Position & $\begin{array}{c}\text { Operation } \\
j\end{array}$ & $\begin{array}{l}\text { Tool } \\
\text { index } \\
r \in R_{j}\end{array}$ & $\begin{array}{l}\text { Tool } \\
\text { and its } \\
\text { material }\end{array}$ & $\begin{array}{l}\text { Part } \\
d\end{array}$ & $\begin{array}{c}L_{j r d} \\
(\mathrm{~mm})\end{array}$ & $l_{j r d}$ & $\begin{array}{c}t_{j r d} \\
(\mathrm{~mm})\end{array}$ & $\begin{array}{c}D_{j r} \\
(\mathrm{~mm})\end{array}$ & \begin{tabular}{|c|}
$\begin{array}{c}B_{j r d} \\
(\mathrm{~mm})\end{array}$ \\
\end{tabular} & $z_{j r}$ & $\begin{array}{c}s_{j r} \\
(\mathrm{~mm} / \\
\mathrm{rev})\end{array}$ & $\widetilde{C}_{r d}$ & $\bar{\rho}_{r d}$ & $\begin{array}{l}g_{1 r} \\
(\$)\end{array}$ & $\begin{array}{c}g_{2 r} \\
(\mathrm{~min})\end{array}$ & $u_{1 j}$ & $u_{2 j}$ & $v_{1 j r}$ & $v_{2 j r}$ \\
\hline \multirow[t]{6}{*}{2} & \multirow[t]{6}{*}{1} & \multirow[t]{3}{*}{1} & \multirow{3}{*}{$\begin{array}{l}\text { Face cutter, } \\
\text { BК8 }\end{array}$} & 1,2 & 144 & 115 & 4.8 & 125 & 95 & 16 & 3.6 & 97.81 & 3.3 & 60 & 4 & \multirow[t]{6}{*}{0.000695} & \multirow[t]{6}{*}{0.002005} & 54.4 & 157.0 \\
\hline & & & & 3 & 149 & 120 & 4.8 & 125 & 50 & 16 & 3.6 & 97.81 & 3.3 & 60 & 4 & & & 54.4 & 157.0 \\
\hline & & & & 4 & 149 & 120 & 4.8 & 125 & 50 & 16 & 3.6 & 97.81 & 3.3 & 60 & 4 & & & 54.4 & 157.0 \\
\hline & & \multirow[t]{3}{*}{2} & \multirow{3}{*}{$\begin{array}{c}\text { Face cutter, } \\
\text { ВК8 }\end{array}$} & 1,2 & 157 & 128 & 4.8 & 160 & 140 & 24 & 3.6 & 97.81 & 3.3 & 60 & 4 & & & 69.6 & 201.0 \\
\hline & & & & 3 & 157 & 128 & 4.8 & 160 & 140 & 24 & 3.6 & 97.81 & 3.3 & 60 & 4 & & & 69.6 & 201.0 \\
\hline & & & & 4 & 157 & 128 & 4.8 & 160 & 90 & 24 & 3.6 & 97.81 & 3.3 & 60 & 4 & & & 69.6 & 201.0 \\
\hline \multirow[t]{6}{*}{3} & \multirow[t]{6}{*}{2} & \multirow[t]{3}{*}{1} & \multirow{3}{*}{$\begin{array}{c}\text { Face cutter, } \\
\text { BK8 }\end{array}$} & 1,2 & 131 & 115 & 1.2 & 125 & 95 & 16 & 2 & 97.81 & 3.3 & 60 & 4 & \multirow[t]{6}{*}{0.000827} & \multirow[t]{6}{*}{0.002386} & 82.3 & 237.5 \\
\hline & & & & 3 & 136 & 120 & 1.2 & 125 & 50 & 16 & 2 & 97.81 & 3.3 & 60 & 4 & & & 82.3 & 237.5 \\
\hline & & & & 4 & 136 & 120 & 1.2 & 125 & 50 & 16 & 2 & 97.81 & 3.3 & 60 & 4 & & & 82.3 & 237.5 \\
\hline & & \multirow[t]{3}{*}{2} & \multirow{3}{*}{$\begin{array}{c}\text { Face cutter, } \\
\text { BK8 }\end{array}$} & 1,2 & 144 & 128 & 1.2 & 160 & 140 & 24 & 2 & 97.81 & 3.3 & 60 & 4 & & & 105.3 & 304.0 \\
\hline & & & & 3 & 144 & 128 & 1.2 & 160 & 140 & 24 & 2 & 97.81 & 3.3 & 60 & 4 & & & 105.3 & 304.0 \\
\hline & & & & 4 & 144 & 128 & 1.2 & 160 & 90 & 24 & 2 & 97.81 & 3.3 & 60 & 4 & & & 105.3 & 304.0 \\
\hline \multirow[t]{4}{*}{4} & \multirow[t]{2}{*}{3} & 1,2 & Drill, P18 & 1,2 & 56 & 45 & 5.25 & 10.5 & - & - & 0.14 & 91.9 & 4.0 & 4 & 2 & \multirow[t]{2}{*}{0.005444} & \multirow[t]{2}{*}{0.020417} & 11.5 & 43.2 \\
\hline & & 3,4 & Drill, P18 & $\begin{array}{c}1,2,3 \\
4\end{array}$ & 56 & 45 & 5.25 & 10.5 & - & - & 0.14 & 91.9 & 4.0 & 4 & 2 & & & 11.5 & 43.2 \\
\hline & \multirow[t]{2}{*}{4} & $5,6,9,10$ & Drill, P18 & $\begin{array}{c}1,2,3 \\
4\end{array}$ & 39 & 25 & 8.25 & 16.5 & - & - & 0.22 & 91.9 & 4.0 & 4 & 2 & \multirow[t]{2}{*}{0.005826} & \multirow[t]{2}{*}{0.021654} & 10.9 & 40.4 \\
\hline & & 7,8 & Drill, P18 & $1,2,3$ & 36 & 25 & 7.25 & 14.5 & - & - & 0.19 & 91.9 & 4.0 & 4 & 2 & & & 11.1 & 41.1 \\
\hline \multirow[t]{3}{*}{5} & \multirow[t]{2}{*}{5} & 1,2 & $\begin{array}{l}\text { Spotfacer, } \\
\text { P18 }\end{array}$ & 1,2 & 12 & 7 & 4.75 & 20 & - & - & 0.2 & 102.3 & 3.9 & 4 & 2 & \multirow[t]{2}{*}{0.007127} & \multirow[t]{2}{*}{0.026725} & 11.8 & 44.0 \\
\hline & & 3,4 & $\begin{array}{l}\text { Spotfacer, } \\
\text { P18 }\end{array}$ & $1,2,3,4$ & 12 & 7 & 4.75 & 20 & - & - & 0.2 & 102.3 & 3.9 & 4 & 2 & & & 11.8 & 44.0 \\
\hline & 6 & $5,6,9,10$ & $\begin{array}{l}\text { Spotfacer, } \\
\text { P18 }\end{array}$ & $1,2,3,4$ & 17 & 12 & 7 & 30.5 & - & - & 0.23 & 102.3 & 3.9 & 4 & 2 & 0.008993 & 0.033725 & 12.4 & 46.3 \\
\hline 6 & 7 & 1,2 & $\begin{array}{l}\text { Core drill, } \\
\text { P18Ф }\end{array}$ & 1,2 & 54 & 45 & 1 & 12.5 & - & - & 0.23 & 91.9 & 4.0 & 4 & 2 & 0.002826 & 0.010599 & 16.1 & 60.4 \\
\hline & & 3,4 & $\begin{array}{l}\text { Core drill, } \\
\text { P18Ф }\end{array}$ & $1,2,3,4$ & 54 & 45 & 1 & 12.5 & - & - & 0.23 & 91.9 & 4.0 & 4 & 2 & & & 16.1 & 60.4 \\
\hline & 8 & $5,6,9,10$ & $\begin{array}{l}\text { Core drill, } \\
\text { P18Ф }\end{array}$ & $1,2,3,4$ & 34 & 25 & 1 & 18.5 & - & - & 0.28 & 91.9 & 4.0 & 4 & 2 & 0.003437 & 0.012588 & 16.5 & 60.4 \\
\hline & & 7,8 & $\begin{array}{l}\text { Core drill, } \\
\text { P18Ф }\end{array}$ & $1,2,3$ & 30 & 25 & 1 & 16.5 & - & - & 0.25 & 91.9 & 4.0 & 4 & 2 & & & 16.5 & 60.3 \\
\hline
\end{tabular}



So in each of positions 4,5 and 6 two operations (i.e. pairs of operations $\{3,4\},\{5,6\}$ and $\{7,8\}$ respectively) are executed. Each such a pair of operations can be aggregated into the respective operation block. Thus (see Section 3), the operation set is $J=\{1,2, \ldots, 8\}$, and the family of potential operation blocks is $W=\left\{w_{1}=\{3,4\}, w_{2}=\{5,6\}, w_{3}=\{7,8\}\right\}$, hence possible options of aggregation of operations are presented by the vector $\boldsymbol{q}=\left(q_{1}, q_{2}, q_{3}\right) \in Q$ and $|Q|=8$.

Each operation block $w \in W$ is to be executed by one multi-spindle head with common driver, while the disaggregated execution of the respective operations should be performed by two individual spindle heads with their own drivers.

The parameters $G_{p l}(\boldsymbol{q})$ in the relations (1) for the four different options $O_{1}, O_{2}, O_{3}, O_{4}$ of annual (batch production) plan and for all feasible $\boldsymbol{q} \in Q$ are given in Table 3. In this table $T^{0}$ is a maximal feasible value of cycle duration for the respective annual plan. It is assumed that values of parameters $G_{11}(\boldsymbol{q})$ and $G_{21}(\boldsymbol{q})$ do not depend on annual plan.

Table 3. Parameters $G_{p l}(\boldsymbol{q})$ of functions $\Phi_{11}(\boldsymbol{q}, \boldsymbol{u})$ and $\Phi_{21}(\boldsymbol{q}, \boldsymbol{u})$

\begin{tabular}{|c|c|c|c|c|c|c|c|c|c|}
\hline$O_{k} / T^{0}$ & $q$ & $(\mathbf{0 , 0 , 0 )}$ & $(\mathbf{0 , 0} \mathbf{0}, \mathbf{1})$ & $(0,1,0)$ & $(0,1,1)$ & $(1,0,0)$ & $(1,0,1)$ & $(1,1,0)$ & $(1,1,1)$ \\
\hline \multirow{2}{*}{$\begin{array}{c}10000 / \\
20.33 \\
\end{array}$} & $G_{10}(q)(\$)$ & & & & & & & & \\
\hline & $G_{20}(\boldsymbol{q})(\mathrm{min})$ & & & & & & & & \\
\hline \multirow{2}{*}{$\begin{array}{c}36400 / \\
5.58\end{array}$} & $G_{10}(\boldsymbol{q})(\$)$ & 1.36 & 1.4 & 1.4 & 1.452 & 1.4 & 1.452 & 1.452 & 1.497 \\
\hline & $G_{20}(\boldsymbol{q})(\mathrm{min})$ & 0.26 & 0.273 & 0.273 & 0.28 & 0.273 & 0.28 & 0.28 & 0.289 \\
\hline \multirow{2}{*}{$\begin{array}{c}38900 / \\
5.22 \\
\end{array}$} & $G_{10}(\boldsymbol{q})(\$)$ & 1.274 & 1.316 & 1.316 & 1.358 & 1.316 & 1.358 & 1.358 & 1.4 \\
\hline & $G_{20}(\boldsymbol{q})(\mathrm{min})$ & 0.25 & 0.263 & 0.263 & 0.27 & 0.263 & 0.27 & 0.27 & 0.278 \\
\hline \multirow{2}{*}{$\begin{array}{c}39500 / \\
5.15 \\
\end{array}$} & $G_{10}(\boldsymbol{q})(\$)$ & 1.255 & 1.296 & 1.296 & 1.3378 & 1.296 & 1.3378 & 1.3378 & 1.3794 \\
\hline & $G_{20}(\boldsymbol{q})(\mathrm{min})$ & 0.24 & 0.252 & 0.252 & 0.259 & 0.252 & 0.259 & 0.259 & 0.266 \\
\hline \multirow{2}{*}{$\begin{array}{c}O_{k}, \\
k=1,2,3,4\end{array}$} & $G_{11}(\boldsymbol{q})(\$ / \mathrm{min})$ & 0.7 & 0.711 & 0.711 & 0.722 & 0.711 & 0.722 & 0.722 & 0.733 \\
\hline & $G_{21}(\boldsymbol{q})$ & 1.1 & 1.103 & 1.103 & 1.106 & 1.103 & 1.106 & 1.106 & 1.109 \\
\hline
\end{tabular}

Table 3 was obtained under the following assumptions. The service life of the transfer machine is 7 years. The number of machine operators is 1 and his labour rate is $7 \$ /$ hour. The number of working hours per year is 3987 for 2 shifts per working day. The availability coefficient of the transfer machine is 0.85 . The overhead rate is 3.3 (taking into account other staff, general running costs and others items). The average utilization rate of the total engine power of the transfer machine is equal to 0.75 . Investment costs $Z_{1}(\boldsymbol{q})$ of the rotary machine for different aggregation options $\boldsymbol{q} \in Q$, the cost $Z_{2}(\boldsymbol{q})$ and time $Z_{3}(\boldsymbol{q})$ for maintenance of the rotary machine per unit of operating time, the total engine power $Z_{4}(\boldsymbol{q})$ of the rotary machine and the energy $\operatorname{cost} Z_{5}(\boldsymbol{q})$ per unit of operating time are given in Table 4. Annual cost of depreciation of the production area and other similar items is equal to $6700 \$$ for all aggregation options of the rotary machine. 
Table 4 Initial data for determining parameters $G_{p l}(\boldsymbol{q})$

\begin{tabular}{|c|c|c|c|c|c|c|c|c|}
\hline $\boldsymbol{q}=\left(q_{1}, q_{2}, q_{3}\right)$ & $\mathbf{( 0 , 0 , 0}$ & $\mathbf{( 0 , 0 , 1 )}$ & $\mathbf{( 0 , 1 , 0 )}$ & $\mathbf{( 0 , 1 , 1 )}$ & $\mathbf{( 1 , 0 , 0 )}$ & $\mathbf{( 1 , 0 , 1 )}$ & $\mathbf{( 1 , 1 , 0 )}$ & $\mathbf{( 1 , 1 , 1 )}$ \\
\hline$Z_{1}(\boldsymbol{q})(\$)$ & 300000 & 311500 & 311500 & 323000 & 311500 & 323000 & 323000 & 334500 \\
\hline$Z_{2}(\boldsymbol{q})(\$ /$ hour $)$ & 4 & 4.15 & 4.15 & 4.3 & 4.15 & 4.3 & 4.3 & 4.45 \\
\hline$Z_{3}(\boldsymbol{q})($ hour$)$ & 0.1 & 0.103 & 0.103 & 0.106 & 0.103 & 0.106 & 0.106 & 0.109 \\
\hline$Z_{4}(\boldsymbol{q})(\mathrm{KWh})$ & 76 & 80 & 80 & 84 & 80 & 84 & 84 & 88 \\
\hline$Z_{5}(\boldsymbol{q})(\$$ /hour $)$ & 7.8 & 8.2 & 8.2 & 8.6 & 8.2 & 8.6 & 8.6 & 9 \\
\hline
\end{tabular}

Parameters $C_{p i j}^{\prime}$ in the relations (24) for $p=1,2, i \in I, j \in J_{i}$ are given in Table 5.

Table 5. Parameters $C_{1 i j}^{\prime}$ and $C_{2 i j}^{\prime}$ (coefficient $10^{-10}$ common for all values is omitted)

\begin{tabular}{|c|c|c|c|c|c|c|c|c|c|c|c|c|c|c|c|c|}
\hline$i$ & \multicolumn{10}{|c|}{1} & \multicolumn{1}{|c|}{2} \\
\hline$j$ & 1 & 2 & 3 & 4 & 5 & 6 & 7 & 8 & 1 & 2 & 3 & 4 & 5 & 6 & 7 & 8 \\
\hline$C_{1 i j}^{\prime}$ & 82.7 & 129.9 & 3.62 & 5.04 & 9.21 & 27.6 & 1.3 & 1.57 & 116.5 & 100.8 & 3.62 & 5.04 & 4.61 & 27.6 & 1.3 & 1.57 \\
\hline$C_{2 i j}^{\prime}$ & 5.51 & 8.66 & 1.81 & 2.52 & 4.6 & 13.8 & 0.65 & 0.79 & 7.77 & 6.72 & 1.81 & 2.52 & 2.3 & 13.8 & 0.65 & 0.79 \\
\hline$i$ & \multicolumn{10}{|c|}{3} \\
\hline$j$ & 1 & 2 & 3 & 4 & 5 & 6 & 7 & 8 & 1 & 2 & 3 & 4 & 5 & 6 & 7 & 8 \\
\hline$C_{1 i j}^{\prime}$ & 116.5 & 141.9 & 3.62 & 3.4 & 4.61 & 27.6 & 0.65 & 1.57 & 116.5 & 141.9 & 7.24 & 5.04 & 4.61 & 27.6 & 0.65 & 1.57 \\
\hline$C_{2 i j}^{\prime}$ & 7.77 & 9.46 & 1.81 & 1.7 & 2.3 & 13.8 & 0.324 & 0.79 & 7.77 & 9.46 & 3.62 & 2.52 & 2.3 & 13.8 & 0.324 & 0.79 \\
\hline$i$ & \multicolumn{10}{|c|}{5} & \multicolumn{10}{|c|}{4.6} \\
\hline$j$ & 1 & 2 & 3 & 4 & 5 & 6 & 7 & 8 & 1 & 2 & 3 & 4 & 5 & 6 & 7 & 8 \\
\hline$C_{1 i j}^{\prime}$ & 97.0 & 141.9 & 7.24 & 5.04 & 9.21 & 27.6 & 0.65 & 1.08 & 97.0 & 129.9 & 7.24 & 5.04 & 9.21 & 27.6 & 1.3 & 1.57 \\
\hline$C_{2 i j}^{\prime}$ & 6.47 & 9.46 & 3.62 & 2.52 & 4.61 & 13.8 & 0.324 & 0.79 & 6.47 & 9.46 & 3.62 & 2.52 & 4.61 & 13.8 & 0.65 & 0.79 \\
\hline
\end{tabular}

\subsection{Optimization results and discussion}

In Table 6, the results of sub-problem $\boldsymbol{B}(\boldsymbol{q})$ solution for different options of $\boldsymbol{q} \in Q$ and plans $O_{1}, O_{2}, O_{3}$ and $O_{4}$ are presented. As can be seen, the optimal value of the objective function $\Phi_{1}(\boldsymbol{q}, \boldsymbol{u})$ for the plan $O_{1}$ is achieved for the aggregation option $\boldsymbol{q}=(0,0,0)$; for the plans $\mathrm{O}_{2}, \mathrm{O}_{3}$ and $\mathrm{O}_{4}$ the optimal aggregation option is $\boldsymbol{q}=(1,0,0)$. For the plan $\mathrm{O}_{4}$, the gain when selecting the aggregation option $\boldsymbol{q}=(1,0,0)$ is more than $6.8 \%$ compared to $\boldsymbol{q}=(0,0,0)$.

The optimal values $u_{j}^{*}\left(\boldsymbol{q}^{*}\right)$ and $S_{j}^{*}\left(\boldsymbol{q}^{*}\right)$ of operation rates $u_{j}$ and feeds per minute $S_{j}=1 / u_{j}$, $j \in J$, for the optimal aggregation options $\boldsymbol{q}^{*}\left(O_{k}\right)$ for different plans $O_{k}$ are presented in Table 7. The optimal values $v_{j r}^{*}\left(\boldsymbol{q}^{*}, u_{j}^{*}\left(\boldsymbol{q}^{*}\right)\right)$ of cutting speed $v_{j r}$ for all tools $r \in R_{j}$ for the optimal values $\boldsymbol{q}^{*}\left(O_{k}\right)$ and operation rates $u_{j}^{*}\left(\boldsymbol{q}^{*}\right)$ are presented in Table 8 . 
Table 6. The results for different annual output and aggregation options

\begin{tabular}{|c|c|c|c|c|c|c|c|c|c|}
\hline & \multicolumn{8}{|c|}{$a$} \\
\hline & & $(\mathbf{0 , 0 , 0 )}$ & $(\mathbf{0 , 0 , 1 )}$ & $(0,1,0)$ & $(0,1,1)$ & $(1,0,0)$ & $(1,0,1)$ & $(1,1,0)$ & $(1,1,1)$ \\
\hline \multirow[t]{2}{*}{$O_{1}$} & $\Phi_{1}\left(\boldsymbol{q}, \boldsymbol{u}^{*}(\boldsymbol{q})\right)$ & 9.2874 & 9.486 & 9.4923 & 9.69 & 9.3191 & 9.51 & 9.524 & 9.715 \\
\hline & $\Phi_{2}\left(\boldsymbol{q}, \boldsymbol{u}^{*}(\boldsymbol{q})\right)$ & 20.33 & 20.376 & 20.376 & 20.414 & 20.376 & 20.414 & 20.414 & 20.444 \\
\hline \multirow[t]{2}{*}{$\mathrm{O}_{2}$} & $\Phi_{1}\left(\boldsymbol{q}, \boldsymbol{u}^{*}(\boldsymbol{q})\right)$ & 5.6917 & 5.766 & 5.7723 & 5.8587 & 5.5991 & 5.6772 & 5.692 & 5.7635 \\
\hline & $\Phi_{2}\left(\boldsymbol{q}, \boldsymbol{u}^{*}(\boldsymbol{q})\right)$ & 5.58 & 5.5966 & 5.5966 & 5.607 & 5.5966 & 5.607 & 5.607 & 5.612 \\
\hline \multirow[t]{2}{*}{$\mathrm{O}_{3}$} & $\Phi_{1}\left(\boldsymbol{q}, \boldsymbol{u}^{*}(\boldsymbol{q})\right)$ & 5.736 & 5.784 & 5.834 & 5.879 & 5.5181 & 5.5836 & 5.6025 & 5.6675 \\
\hline & $\Phi_{2}\left(\boldsymbol{q}, \boldsymbol{u}^{*}(\boldsymbol{q})\right)$ & 5.22 & 5.2366 & 5.2366 & 5.2472 & 5.2366 & 5.2472 & 5.2472 & 5.2588 \\
\hline \multirow[t]{2}{*}{$\mathrm{O}_{4}$} & $\Phi_{1}\left(\boldsymbol{q}, \boldsymbol{u}^{*}(\boldsymbol{q})\right)$ & 5.8862 & 5.8804 & 6.0202 & 5.9893 & 5.5096 & 5.57 & 5.5958 & 5.6552 \\
\hline & $\Phi_{2}\left(\boldsymbol{q}, \boldsymbol{u}^{*}(\boldsymbol{q})\right)$ & 5.15 & 5.1656 & 5.1656 & 5.1762 & 5.1656 & 5.1762 & 5.1762 & 5.1868 \\
\hline
\end{tabular}

Table 7. The optimal values $u_{j}^{*}\left(\boldsymbol{q}^{*}\right)$ and $S_{j}^{*}\left(\boldsymbol{q}^{*}\right)$ of operation rates $u_{j}$ and feeds per minute $S_{j}$

\begin{tabular}{|c|c|c|c|c|c|c|c|c|c|}
\hline Output & $j$ & 1 & 2 & 3 & 4 & 5 & 6 & 7 & 8 \\
\hline $\begin{array}{c}O_{1}, \\
\boldsymbol{q}^{*}\left(O_{1}\right)\end{array}$ & $u_{j}^{*}$ & 0.0020051 & 0.0023865 & 0.0095468 & 0.0095468 & 0.0267252 & 0.026725 & 0.0099004 & 0.0099004 \\
\cline { 2 - 9 } & $S_{j}^{*}$ & 498.7231 & 419.0264 & 104.7468 & 104.7468 & 37.4178 & 37.4178 & 101.0058 & 101.0058 \\
\hline $\begin{array}{c}O_{2}, \\
\boldsymbol{q}^{*}\left(O_{2}\right)\end{array}$ & $u_{j}^{*}$ & 0.0020051 & 0.0023865 & 0.0089628 & 0.0128697 & 0.0267252 & 0.026725 & 0.0092948 & 0.0092948 \\
\cline { 2 - 9 } & $S_{j}^{*}$ & 498.7231 & 419.0264 & 111.5719 & 77.7019 & 37.4178 & 37.4178 & 107.5872 & 107.5872 \\
\hline $\begin{array}{c}O_{3}, \\
\boldsymbol{q}^{*}\left(O_{3}\right)\end{array}$ & $u_{j}^{*}$ & 0.0020051 & 0.0023865 & 0.0086972 & 0.0124882 & 0.0267252 & 0.026725 & 0.0090193 & 0.0090193 \\
\cline { 2 - 9 } & $S_{j}^{*}$ & 498.7231 & 419.0264 & 114.9802 & 80.0755 & 37.4178 & 37.4178 & 110.8737 & 110.8737 \\
\hline \multirow{2}{*}{$O_{4}}$, & $\boldsymbol{q}_{j}^{*}\left(O_{4}\right)$ & 0.0020051 & 0.0023865 & 0.0084355 & 0.0121125 & 0.0267252 & 0.026725 & 0.0087479 & 0.0087479 \\
\cline { 2 - 9 } & $S_{j}^{*}$ & 498.7231 & 419.0264 & 118.5468 & 82.5594 & 37.4178 & 37.4178 & 114.313 & 114.313 \\
\hline
\end{tabular}

Table 8. The optimal values $v_{j r}^{*}\left(\boldsymbol{q}^{*}, u_{j}^{*}\left(\boldsymbol{q}^{*}\right)\right)$ of cutting speed $v_{j r}$

\begin{tabular}{|c|c|c|c|c|c|c|c|c|c|c|c|c|}
\hline Position & \multicolumn{2}{|c|}{2} & \multicolumn{2}{|c|}{3} & \multicolumn{3}{c|}{4} & \multicolumn{2}{c|}{5} & \multicolumn{2}{c|}{6} \\
\hline$j$ & \multicolumn{2}{|c|}{1} & \multicolumn{2}{|c|}{2} & 3 & 4 & 5 & 6 & 7 & \multicolumn{2}{c|}{8} \\
\hline$r$ & 1 & 2 & 1 & 2 & $1,2,3,4$ & $1,2,5,6$ & 3,4 & $1,2,3,4$ & $1,2,5,6$ & $1,2,3,4$ & $1,2,5,6$ & 3,4 \\
\hline$O_{1}$ & 54.4 & 69.63 & 82.28 & 105.3 & 24.68 & 24.68 & 25.11 & 11.755 & 15.588 & 17.246 & 20.966 & 20.94 \\
\hline$O_{2}$ & 54.4 & 69.63 & 82.28 & 105.3 & 26.288 & 18.308 & 18.63 & 11.755 & 15.588 & 18.369 & 22.33 & 22.31 \\
\hline$O_{3}$ & 54.4 & 69.63 & 82.28 & 105.3 & 27.09 & 18.867 & 19.2 & 11.755 & 15.588 & 18.93 & 23.01 & 22.99 \\
\hline$O_{4}$ & 54.4 & 69.63 & 82.28 & 105.3 & 27.932 & 19.453 & 19.794 & 11.755 & 15.588 & 19.518 & 23.728 & 23.702 \\
\hline
\end{tabular}

The models and methods proposed in this work determine optimal design solutions for each specific production system and situation (data).

The results obtained using the proposed models and methods for this use case (and other test cases studied by the authors) lead to the following observations:

1. The optimality of the options for aggregating operations depends on the required annual plan. With its increasing, the positive effect of aggregated execution of some potential operation block is reduced, since the decrease in the unit investment cost is overlapped by the increase in 
unit operating costs due to common rate for all operations of this block (i.e. non-optimal operation rates for each operation separately).

2. A given annual plan limits the ability of aggregated execution of some blocks due to narrowing the ranges of the possible common operation rates for the operations of these block. For the considered case study, the maximal productivity 41300 batches/year (i.e. the lowest possible value of the total cycle time $T^{0}=4.92 \mathrm{~min}$ ) is achieved for the completely disaggregated option $\boldsymbol{q}=(1,1,1)$. The maximal productivity for the completely aggregated option $\boldsymbol{q}=(0,0,0)$ is only 39570 batches/year $\left(T^{0}=5.139 \mathrm{~min}\right)$.

3. The effect of aggregation of operations the less, the more the number of different features to be machined by the potential operation block and the greater the difference in parameters (in particular, diameters and lengths) of these features.

4. For an aggregation option that is optimal for some annual plans, a range of annual plans for which this option remains optimal can be defined. In particular, when the plan is less than a certain "boundary" one, the aggregated option for all potential blocks becomes preferable.

These observations are in good agreement with the properties of rational design solutions for this class of production systems.

\section{Conclusion}

A lot of processes in different application fields (not only manufacturing systems) can be described as sequential execution of a collection of some intersecting operation sets. In this paper, such a class of problems is considered on an example of a problem of structuralparametric optimization of the manufacturing processes of multi-product batch machining on multi-position transfer lines composed of rotary machines is considered. A mathematical model and a method for solving a rather wide class of problems of joint optimization of aggregation of operations of a given collection and the rates of operation execution is proposed. The proposed mathematical model and method can be used for such problems in other applications.

The model is formed in terms of mixed integer nonlinear programming and a two-level decomposition scheme to solve it is developed. The upper level sub-problem of the proposed decomposition scheme consists in selecting an aggregation option of operations into blocks. The lower level sub-problem is to determine the execution rates of all operations for fixed aggregation option. The method of approximate solution of the first sub-problem is based on the combination of heuristic methods and a special version of the method of sequential fixing of variables. A widespread in practice special case of the lower level sub-problem is when the cost and the time spent for each of operations are convex functions of their rates. The method 
proposed for its solution is based on approximation of this problem by a linear programming problem.

The problem statement and its mathematical model are illustrated with one real life design problem for spindle head aggregation/disaggregation options in machining environment for the design of a rotary machine. The experiments have confirmed very good performance of the proposed methods.

This is a general approach which can be applied to different problems of this type in different real life application domains. Similar problems may arise for example at the design stage for various production systems (in particular, assembly/disassembly lines, lines for testing/repairing complex equipment, etc.) as well as for organizations and service systems.

The promising areas of further research include the following:

- studying a wider class of problems when:

- a partial aggregation of operations in blocks is allowed (in particular, potential blocks of one position can intersect);

- the opportunities for aggregation and disaggregation of operations at positions are limited by certain additional conditions (in particular, there are restrictions on the number of blocks of operations at some positions);

- developing effective methods for exact and approximate solution of the original problem with non-convex functions of cost and time of operations on their execution rates;

- developing an iterative scheme for solving the original problem, involving sequential approximation refinement relations according to the previously obtained solutions;

- developing methods to determine the stability region of solutions;3

- show the applicability of the approach in many other real life industrial domains.

\section{Disclosure statement}

No potential conflict of interest was reported by the authors.

\section{Acknowledgments}

The authors thank E.Tsvirko who performed numerical experiments to verify the proposed methods. This work was partially supported by the region Pays de la Loire (Program "Strategical Recrutment"), France.

\section{References}

Alting, L., and H. Zhang. 1989. "Computer Aided Process Planning: the state-of-the-art survey." International Journal of Production Research, 27(4): 553-585.

Arezoo, B., K. Ridgway, and A.M.A. Al-Ahmari. 2000. "Selection of cutting tools and conditions of machining operations using an expert system." Computers in Industry, 42: 43-58. 
Baranovsky, Ju.V., ed. 1972. Metal Cutting Conditions. Handbook. 3th ed. Moscow: Mechinical engineering. (In Russian).

Battaïa, O., A. Dolgui. 2013. "A taxonomy of line balancing problems and their solution approaches." International Journal of Production Economics, 142(2): 259-277.

Battaïa, O., A. Dolgui, and N. Guschinsky. 2017. "Decision support for design of reconfigurable rotary machining systems for family part production." International Journal of Production Research, 55(5): 1368-1385.

Bennett, D. P., and C. A. Yano. 2004. "A decomposition approach for an equipment selection and multiple product routing problem incorporating environmental factors." European Journal of Operational Research, 156: 643-664.

Boysen, N. A., M. Fliedner, and A.Scholl. 2007. "A classification of assembly line balancing problems.” European Journal of Operational Research 183: 674-693.

Bukchin, J., and J. Rubinovitz. 2003. "A weighted approach for assembly line design with station paralleling and equipment selection." IIE Transactions, 35: 73-85.

Bukchin, J., and M. Tzur. 2000. "Design of flexible assembly line to minimize equipment cost." IIE Transactions 32: 585-598.

Cakir, M. C., and A. Gurarda. 2000. "Optimization of machining conditions for multi-tool milling operations." International Journal of Production Research 38(15): 3537-3552.

Dolgui, A., N. Guschinsky, and G. Levin. 2009. "Graph approach for optimal design of transfer machine with rotary table." International Journal of Production Research 47(2): 321-341.

Dolgui, A., G. Levin, B. Rozin, and I. Kasabutski. 2016. "Cost optimization for series-parallel execution of a collection of intersecting operation sets." Engineering Optimization 48 (5): 756-771.

Gupta, D.P., B. Gopalakrishnan, S.A. Chaudhari, and S. Jalali. 2011. "Development of an integrated model for process planning and parameter selection for machining processes." International Journal of Production Research 49(21): 6301-6319.

Halevi, G. 2003. Process and Operation Planning, Dordrecht: Springer.

Kara, Y., C. Ozguven, N. Yalcin, and Y. Atasagun. 2011. "Balancing straight and U-shaped assembly lines with resource dependent task times." International Journal of Production Research 49(21): 6387-6405.

Koren, Y., X. Gu and W. Guo. 2018. "Choosing the system configuration for high-volume manufacturing." International Journal of Production Research, 56(1-2): 476-490.

Levin, G., and B. Rozin. 2009. "Optimization of machining modes for multi-head machines under group replacement of tools." Proceedings of the 13th IFAC Symposium on Information Control Problems in Manufacturing (INCOM09), Moscow, Russia, June 3-5, N. Bakhtadze, A. Dolgui (Eds.), Elsevier Science, 2009, IFAC-PapersOnline.net (ISSN 1474-6670): 11251130.

Levin, G., B. Rozin, and A. Dolgui. 2012. "Optimization of Multi-tool Cutting Modes for Batch Manufacturing in Large Series Machining Environment." Proceedings of the 14th IFAC Symposium on Information Control Problems in Manufacturing (INCOM12), Bucharest, Romania, May 23-25, 2012, T. Borangiu, I. Dumitrache, A. Dolgui, F. Filip (Eds.), Elsevier Science, 2012, IFAC-PapersOnline.net (ISSN 1474-6670): 444-448.

Levin, G., B. Rozin, and A. Dolgui. 2014. "Linear approximation of the problem of optimization of intensities of series-parallel execution of intersecting operation sets." Informatics 3: 44-51. (In Russian).

Levin, G., B. Rozin, and A. Dolgui. 2016. "Optimization of the Structure and Execution Modes of Intersecting Operation Sets." Proceedings of the $8^{\text {th }}$ IFAC conference on Modelling, Management and Control (MIM 2016), Troyes, France, June 28-30, 2016, IFACPapersOnline.net 49-12: 105-110.

Levin, G. and V. Tanaev. 1978. Decomposition methods for optimizing design solutions. Minsk: 
Nauka i technika. (In Russian)

Mohapatra, P., L. Benyoucef and M.K. Tiwari. 2013. "Integration of process planning and scheduling through adaptive setup planning: a multi-objective approach." International Journal of Production Research, 49, (23-24): 7190-7208.

Rozin, B., G. Levin, and A. Dolgui. 2013. "Optimization of Multi-tool Cutting Modes in Multiitem Batch Manufacturing System." Proceedings of the IFAC Conference on Manufacturing Modelling, Management and Control (MIM'2013), St Petersburg, Russia, June 19-21, 2013, N. Bakhtadze, A. Dolgui, V. Lototsky (Eds.), Elsevier Science, IFAC-PapersOnline.net (ISSN 1474-6670): 766-771.

Singh, D.K.J., and C. Jebaraj. 2005. "Feature-based design for process planning of machining processes with optimization using genetic algorithms." International Journal of Production Research 43(18): 3855-3887.

Szadkowski, J. 1971.“An approach to machining process optimization.” International Journal of Production Research 9 (3): 371-376.

\section{Appendix}

Table A1. The summary of notations used in the mathematical model

\begin{tabular}{|l|l|}
\hline \multicolumn{1}{|c|}{ Indexes } & \\
\hline$i$ & the index of the takt in the cycle of the batch $\delta$ processing \\
\hline$k$ & the index of the position of the single-flow transfer line \\
\hline$\chi(i, k)$ & the index of the part $d_{i k}=\delta_{\chi}(i, k)$ of the batch $\delta$ located in the takt $i$ in position $k$ \\
\hline$j$ & the index of the operation \\
\hline$k(j)$ & the index of the position at which the operation $j$ is executed \\
\hline Input Data & \\
\hline$d$ & the part \\
\hline$M$ & the set of parts processed at the transfer line \\
\hline$\delta$ & the batch $\left\{\delta_{1}, \ldots, \delta_{n}\right\}$ of parts $\delta_{s} \in M, s=1,2, \ldots, n$ to be processed \\
\hline$n$ & the number of parts in the batch $\delta$ \\
\hline$d_{i k}$ & the part of the batch $\delta$ located in the takt $i$ in position $k$ of the line \\
\hline$d_{i j}$ & the part of the batch $\delta$ machined by the operation $j$ in this takt $i$ \\
\hline$J$ & $\begin{array}{l}\text { the given set of all operations executed at all line positions for all parts of the } \\
\text { batch } \delta\end{array}$ \\
\hline$J_{i}$ & the subset of the operations from $J$ executed in takt $i \in I$ \\
\hline$I$ & the set $\{1, \ldots, i, \ldots, n\}$ of takt indexes of the cycle of the batch $\delta$ processing \\
\hline$L_{j d}$ & $\begin{array}{l}\text { the working stroke of the respective drive unit for operation } j \text { when machining } \\
\text { the part } d\end{array}$ \\
\hline$S_{j}$ & the given range $\left[S_{j 1}, S_{j 2}\right]$ of feed per minute $S_{j}$ \\
\hline$w$ & the given non-unit nonintersecting subset of operations from $J$ \\
\hline$W$ & the family of subsets $w$ of operations that may form operation blocks \\
\hline$I(w)$ & the subset of takts that comprise operations from $w$ \\
\hline$L_{w d}$ & $\begin{array}{l}\text { the common working stroke (for } q_{w}=0 \text { ) of all operations } j \in w \text { when machining } \\
\text { the part } d\end{array}$ \\
\hline$U_{j}$ & the set of possible options of vector $q$ \\
\hline$L_{i j}$ & the set of possible values of rate $u_{j}$ of the operation $j$ \\
\hline & the volume" of operation $j$ in takt $i$ \\
\hline & \\
\hline
\end{tabular}




\begin{tabular}{|c|c|}
\hline $\boldsymbol{U}$ & the set of possible rates $u_{j}$ of all operations $j \in J$ \\
\hline$\underline{\boldsymbol{U}_{w}}$ & the set of possible rates $u_{j}$ of the operations $j \in w$ of the operation block $w$ \\
\hline$\underline{U}(q)$ & $\begin{array}{l}\text { the set of possible vectors } \boldsymbol{u} \in \boldsymbol{U} \text { for fixed option } \boldsymbol{q} \text { of operations } j \in w \\
\text { aggregation, for all } w \in W\end{array}$ \\
\hline$G_{p 0}(\boldsymbol{q})$ & $\begin{array}{l}\text { the components of cost }(p=1) \text { and time }(p=2) \text { related to a single cycle of } \\
\text { machining } \delta \text { that do not depend on the cycle net duration }\end{array}$ \\
\hline$G_{p 1}(\boldsymbol{q})$ & the values of $\operatorname{cost}(p=1)$ and time $(p=2)$ per unit of the cycle net duration \\
\hline$E_{p l}$ & the components of $G_{p l}(\boldsymbol{q})$ that do not depend on aggregation of operations \\
\hline$E_{p l w}, e_{p l w}$ & $\begin{array}{l}\text { the piece of the cost (or time) related to aggregated or disaggregated executing } \\
\text { the operations of } w \text { respectively }\end{array}$ \\
\hline$\widetilde{E}_{p}(\boldsymbol{q})$ & $\begin{array}{l}\text { the cost }(p=1) \text { or the time }(p=2) \text { of maintenance of equipment and its depreciation } \\
\text { per unit of cycle duration execution for fixed } q\end{array}$ \\
\hline$t_{b i}$ & the auxiliary time (e.g. duration of idle movements) in takt $i$ \\
\hline$T^{0}$ & the upper bound of the cycle time of the batch $\delta$ processing \\
\hline$R_{j}$ & the set of tools executing the operation $j \in J$ \\
\hline $\begin{array}{l}L_{j r d}, l_{j r d}, t_{j r d}, \\
B_{j r d}\end{array}$ & $\begin{array}{l}\text { the working stroke, the cutting length, the depth of cut and the machining width } \\
\text { respectively for the tool } r \text { in the operation } j \text { when machining the part } d\end{array}$ \\
\hline$D_{j r}, z_{j r}, s_{j r}$ & $\begin{array}{l}\text { the diameter, the number of teeth (for cutter) and the feed per revolution } \\
\text { respectively of the tool } r \text { in the operation } j\end{array}$ \\
\hline$u_{1 j}, u_{2 j}$ & the lower and upper bounds of the range of operation $j$ rate \\
\hline$v_{1 j r}, v_{2 j r}$ & $\begin{array}{l}\text { the lower and upper bounds of the range of cutting speed for the tool } r \text { in the } \\
\text { operation } j\end{array}$ \\
\hline $\bar{C}_{r d \mu}, \bar{\rho}_{r d \mu}, \bar{\mu}_{r d}$ & the parameters in the relation (2) for the tool $r$ when machining the part $d$ \\
\hline$\widetilde{C}_{r d}, \bar{\rho}_{r d}$ & $\begin{array}{l}\text { the parameters in the relation (2) for the tool } r \text { when machining the part } d \text { for } \\
\bar{\mu}_{r d}=1\end{array}$ \\
\hline$g_{1 r}, g_{2 r}$ & the cost and time spent on one replacement of the tool $r$ \\
\hline \multicolumn{2}{|l|}{$\begin{array}{l}\text { Variables, } \\
\text { Sets }\end{array}$} \\
\hline$S_{j}$ & the feed per minute for operation $j$ \\
\hline$u_{j}$ & the operation $j$ rate $\left(1 / S_{j}\right)$ \\
\hline$\underline{u_{w}}$ & the rate of the block $w$ of operations $\left(q_{w}=0\right)$ \\
\hline$q_{w}$ & $\begin{array}{l}\text { the variable indicating the manner of execution of all operations from subset } w \text { : } \\
q_{w}=0 \text { if they are executed in aggregate manner and } q_{w}=1 \text { otherwise }\end{array}$ \\
\hline$q$ & the vector $\left(q_{w} \mid w \in W\right)$ of the components $q_{w}, w \in W$ \\
\hline$u$ & the vector $\left(u_{j} j \in J\right)$ of rates $u_{j}$ of operations $j \in J$ \\
\hline$J^{1}(q)$ & the subset of operations executed in disaggregate manner for fixed $\boldsymbol{q} \in Q$ \\
\hline$W^{0}(\boldsymbol{q})$ & $\begin{array}{l}\text { the subset of operation blocks from } W \text { executed in aggregate manner for fixed } \\
\boldsymbol{q} \in Q\end{array}$ \\
\hline$W_{i}^{0}(\boldsymbol{q})$ & the subset of operation blocks that include operations executed in takt $i$ \\
\hline$u(q)$ & the vector $\left(u_{j} j j \in J^{1}(\boldsymbol{q})\right)$ of rates of operations $j \in J^{1}(\boldsymbol{q})$ \\
\hline$\underline{u}(q)$ & the vector $\left(\underline{u}_{w} \mid w \in W^{0}(\boldsymbol{q})\right)$ of rates of operation blocks $w \in W^{0}(\boldsymbol{q})$ \\
\hline$\Lambda_{i w}$ & the volume of potential operation block $w \in W$ executed in takt $i \in I$; \\
\hline$u_{j}^{*}(\boldsymbol{q})$ & the optimal rate of the operation $j$ for fixed $q$ \\
\hline$S_{j}^{*}(\boldsymbol{q})$ & the optimal feed per minute of the operation $j$ for fixed $q$ \\
\hline$q^{*}\left(O_{k}\right)$ & the optimal vector $\boldsymbol{q} \in Q$ for given production plan $O_{k}$ \\
\hline
\end{tabular}




\begin{tabular}{|c|c|}
\hline$v_{j r}^{*}\left(\boldsymbol{q}, u_{j}^{*}(\boldsymbol{q})\right)$ & the optimal value of cutting speed $v_{j r}$ for fixed $q$ \\
\hline$q^{0}$ & the initial value of vector $\boldsymbol{q}$ from which the algorithm MSFV starts \\
\hline$q^{c}$ & the current value of vector $\boldsymbol{q}$ in the algorithm MSFV \\
\hline$Q\left(\boldsymbol{q}^{c}\right)$ & $\begin{array}{l}\text { the sequence of vectors from } Q \text { that differ from } \boldsymbol{q}^{c} \text { by one of its non-fixed } \\
\text { components }\end{array}$ \\
\hline$\Psi$ & the set of $w \in W$ with fixed values of component $\boldsymbol{q}_{w}$ for current vector $\boldsymbol{q}^{c}$ \\
\hline$\underline{q}(\boldsymbol{q}, w)$ & the vector from $Q$ that differs from vector $\boldsymbol{q} \in Q$ only by the component $q_{w}$ \\
\hline $\mathrm{B}(\boldsymbol{q}), \mathrm{C}$ & the sub-problems in the decomposition scheme of the problem $\mathbf{A}$ \\
\hline \multicolumn{2}{|l|}{ Functions } \\
\hline$f_{p i j}\left(u_{j}\right)$ & $\begin{array}{l}\text { the cost }(p=1) \text { and time }(p=2) \text { of operation } j \text { in takt } i \text { (i.e. when machining the } \\
\left.\text { part } d_{i j}\right) \text { related to the consumption of tools per one cycle of machining the } \\
\text { batch } \delta \text { for fixed } u_{j} \in U_{j}\end{array}$ \\
\hline$\Phi_{1}(\boldsymbol{q}, \boldsymbol{u})$ & the total cost for machining one batch $\delta$ of parts \\
\hline$\Phi_{2}(\boldsymbol{q}, \boldsymbol{u})$ & the total time for machining one batch $\delta$ of parts \\
\hline$\Theta_{1}(\boldsymbol{q}, \boldsymbol{u})$ & the total cost for machining one batch $\delta$ of parts minus $G_{10}(\boldsymbol{q})$ \\
\hline$\Theta_{2}(q, u)$ & the total time for machining one batch $\delta$ of parts minus $G_{20}(q)$ \\
\hline$\widetilde{f_{p j}}\left(u_{j}\right)$ & $\begin{array}{l}\text { the functions of the cumulative cost }(p=1) \text { and of the cumulative time }(p=2) \\
\text { respectively for operation } j \in J \text { on its rate } u_{j} \text { in single execution of one cycle of } \\
\text { batch } \delta \text { machining }\end{array}$ \\
\hline$\hat{f}_{p w}\left(\underline{u}_{w}\right)$ & $\begin{array}{l}\text { the functions of the cumulative cost }(p=1) \text { and of the cumulative time }(p=2) \\
\text { respectively for operation block } w \in W \text { on its rate } \underline{u}_{w} \text { in single execution of one } \\
\text { cycle of batch } \delta \text { machining }\end{array}$ \\
\hline$\widetilde{\Theta}_{1}(\boldsymbol{u}(\boldsymbol{q}), \underline{u}(\boldsymbol{q}))$ & the objective function $\Theta_{1}(\boldsymbol{q}, \boldsymbol{u})$ in the subproblem $\mathbf{B}(\boldsymbol{q})$ in terms of $\boldsymbol{u}(\boldsymbol{q}), \underline{\boldsymbol{u}}(\boldsymbol{q})$ \\
\hline$\widetilde{\Theta}_{2}(\boldsymbol{u}(\boldsymbol{q}), \underline{\boldsymbol{u}}(\boldsymbol{q}))$ & $\begin{array}{l}\text { the left side function } \Theta_{2}(\boldsymbol{q}, \boldsymbol{u}) \text { of the constraint in the sub-problem } \mathbf{B}(\boldsymbol{q}) \text { in terms } \\
\text { of } \boldsymbol{u}(\boldsymbol{q}), \underline{\boldsymbol{u}}(\boldsymbol{q})\end{array}$ \\
\hline$T_{r d_{i j}}\left(u_{j}\right)$ & $\begin{array}{l}\text { the tool } r \text { life time under assumption that it machines only the parts } d_{i j} \text { at } \\
\text { operation rate } u_{j}\end{array}$ \\
\hline$N_{i j r}\left(u_{j}\right)$ & $\begin{array}{l}\text { the estimated number of parts } d_{i j} \text { machined by the tool } r \text { during its life time at } \\
\text { operation rate } u_{j}\end{array}$ \\
\hline$H(\boldsymbol{q})$ & $\begin{array}{l}\text { the value } \Theta^{*}(\boldsymbol{q})+G_{10}(\boldsymbol{q}) \text {, where } \Theta^{*}(\boldsymbol{q}) \text { is the optimal value in the sub-problem } \\
\mathbf{B}(\boldsymbol{q}) \text { for given } \boldsymbol{q}\end{array}$ \\
\hline
\end{tabular}

